\title{
Invasion suppressor cystatin E/M (CST6): high-level cell type-specific expression in normal brain and epigenetic silencing in gliomas
}

Jingxin Qiu', Lingbao $\mathrm{Ai}^{2}$, Cheppail Ramachandran ${ }^{3}$, Bing $\mathrm{Yao}^{2}$, Suhasni Gopalakrishnan ${ }^{2}, \mathrm{C}$ Robert Fields ${ }^{2}$, Amber L Delmas ${ }^{2}$, Lisa M Dyer ${ }^{2}$, Steven J Melnick ${ }^{3}$, Anthony T Yachnis ${ }^{1}$, Philip H Schwartz ${ }^{4}$, Howard A Fine ${ }^{5}$, Kevin D Brown ${ }^{2}$ and Keith D Robertson ${ }^{2}$

DNA hypermethylation-mediated gene silencing is a frequent and early contributor to aberrant cell growth and invasion in cancer. Malignant gliomas are the most common primary brain tumors in adults and the second most common tumor in children. Morbidity and mortality are high in glioma patients because tumors are resistant to treatment and are highly invasive into surrounding brain tissue rendering complete surgical resection impossible. Invasiveness is regulated by the interplay between secreted proteases (eg, cathepsins) and their endogenous inhibitors (cystatins). In our previous studies we identified cystatin E/M (CST6) as a frequent target of epigenetic silencing in glioma. Cystatin E/M is a potent inhibitor of cathepsin B, which is frequently overexpressed in glioma. Here, we study the expression of cystatin E/M in normal brain and show that it is highly and moderately expressed in oligodendrocytes and astrocytes, respectively, but not in neurons. Consistent with this, the CST6 promoter is hypomethylated in all normal samples using methylation-specific PCR, bisulfite genomic sequencing, and pyrosequencing. In contrast, $78 \%$ of 28 primary brain tumors demonstrated reduced/absent cystatin E/M expression using a tissue microarray and this reduced expression correlated with CST6 promoter hypermethylation. Interestingly, CST6 was expressed in neural stem cells (NSC) and markedly induced upon differentiation, whereas a glioma tumor initiating cell (TIC) line was completely blocked for CST6 expression by promoter methylation. Analysis of primary pediatric brain tumor-derived lines also showed CST6 downregulation and methylation in nearly $100 \%$ of 12 cases. Finally, ectopic expression of cystatin E/M in glioma lines reduced cell motility and invasion. These results demonstrate that epigenetic silencing of CST6 is frequent in adult and pediatric brain tumors and occurs in TICS, which are thought to give rise to the tumor. CST6 methylation may therefore represent a novel prognostic marker and therapeutic target specifically altered in TICs.

Laboratory Investigation (2008) 88, 910-925; doi:10.1038/labinvest.2008.66; published online 7 July 2008

KEYWORDS: cell invasion; CST6; cystatin E/M; DNA methylation; glioma; neural stem cell

Methylation at the 5-position of cytosine within the CpG dinucleotide in mammalian cells is an essential mechanism for repressing gene activity and maintaining genomic stability. Proper establishment and maintenance of genome-wide DNA methylation patterns is essential for embryonic development and cellular differentiation. ${ }^{1}$ Although essential for normal cellular functions, methylation patterns are universally disrupted in cancers. Tumor cells exhibit global hypomethylation of the genome accompanied by regionspecific hypermethylation events. ${ }^{2}$ The majority of the hypomethylation occurs in repetitive DNA regions leading to increased mitotic recombination. ${ }^{3,4}$ In contrast, CpG

\footnotetext{
${ }^{1}$ Department of Pathology, UF-Shands Cancer Center Program in Cancer Genetics, Epigenetics, and Tumor Virology, University of Florida College of Medicine, Gainesville, FL, USA; ${ }^{2}$ Department of Biochemistry and Molecular Biology, UF-Shands Cancer Center Program in Cancer Genetics, Epigenetics, and Tumor Virology, University of Florida College of Medicine, Gainesville, FL, USA; ${ }^{3}$ Department of Pathology, Miami Children's Hospital, Miami, FL, USA; ${ }^{4}$ National Human Neural Stem Cell Resource, Children's Hospital of Orange County Research Institute, Orange, CA, USA and ${ }^{5}$ Neuro-Oncology Branch, National Cancer Institute, National Institutes of Health, Bethesda, MD, USA

Correspondence: Dr KD Robertson, Department of Biochemistry and Molecular Biology, University of Florida College of Medicine, Box 100245,1600 SW Archer Rd., Gainesville, FL 32610, USA.
}

E-mail: keithr@ufl.edu

Received 31 March 2008; revised 05 May 2008; accepted 06 May 2008 
island promoter regions are frequently subject to aberrant hypermethylation events. Abnormal methylation of $\mathrm{CpG}$ islands efficiently represses transcription of the associated gene in a manner akin to deletion and acts as one of the 'hits' in the Knudsen model. ${ }^{2,5}$

Numerous lines of evidence indicate that aberrant DNA methylation patterns have a direct causal role in carcinogenesis and occur early during transformation. For example, use of genome-wide restriction landmark genomic scanning to analyze the methylation status of $1184 \mathrm{CpG}$ islands from 98 tumor samples revealed widespread $\mathrm{CpG}$ island de novo methylation in tumor cells (up to $10 \%$ of CpG islands were affected). ${ }^{6}$ Genes regulating cell migration and invasion are also frequent targets for epigenetic silencing. For example, the matrix metalloproteinase (MMP) inhibitor tissue inhibitor of metalloproteinase-3 (TIMP-3) is silenced by promoter hypermethylation in $\sim 30 \%$ of gliomas. ${ }^{7}$ Multiple MMP's and the serine protease inhibitor maspin are epigenetically silenced in pancreatic and gastric cancer, respectively. ${ }^{8,9}$ More recent studies, including those from our group, ${ }^{10}$ have demonstrated that aberrant DNA methylation and histone modifications are common in malignant glioma and likely play a significant role in gliomagenesis. ${ }^{1-13}$ Thus, ample evidence exists to support the notion that DNA hypermethylation acts as a primary inactivating event contributing directly to tumorigenesis, invasion, and metastasis. Importantly, epigenetic changes are reversible with currently available pharmaceuticals (5-aza-2'-deoxycytidine (5-azadC), for example) and there is significant interest in optimizing use of these agents singly, or in combination with other agents, for the treatment of human cancer patients. ${ }^{14}$ Aberrant epigenetic marks may also provide new targets for therapeutic intervention and biomarkers for disease detection and/or prognosis. ${ }^{15}$

High-grade glial tumors (anaplastic astrocytoma (AA) and glioblastoma multiforme (GBM)) are the most frequent type of primary brain tumor in adults. ${ }^{16,17}$ Morbidity and mortality from malignant glioma is directly correlated with the ability of tumor cells to infiltrate surrounding tissues. Malignant cells are found well beyond the gross radiographic margins of the tumor and their invasive nature makes it impossible to obtain a clear surgical resection margin, therefore, following surgical debulking and/or radiation therapy, residual tumor cells eventually lead to relapse, usually within $2 \mathrm{~cm}$ of the original lesion. ${ }^{18-20}$ Glioma cell invasion is likely an early event in disease progression as elevated normal tissue invasion is often observed in lowgrade infiltrating astrocytomas. ${ }^{18}$

Pediatric brain tumors are the second most common type of pediatric cancer after leukemia and are the leading cause of cancer-related deaths in the pediatric population. They are a heterogeneous group of tumors that vary in their age of onset, histology, and prognosis. Astrocytomas account for $52 \%$ of pediatric brain tumors, medulloblastoma/primitive neuroectodermal tumors $21 \%$, ependymomas $9 \%$, and other gliomas $15 \% .{ }^{21}$ Genetic alterations in pediatric brain tumors vary with tumor type and also show some distinct differences from adult brain tumors. ${ }^{22}$ The contribution of epigenetic changes to the development of pediatric brain tumors has not been extensively studied, although genes known to be targeted for epigenetic silencing in other tumor types, such as O6-methylguanine DNA methyltransferase and TIMP3 are hypermethylated in oligodendrogliomas, ependymomas, and pilocytic astrocytomas at varying frequencies. ${ }^{23,24}$

A number of secreted proteolytic enzymes play roles in glioma cell invasiveness. CNS tissues contain representatives of the three major groups of proteases and their endogenous inhibitors: matrix metalloproteases (MMPs) and tissue inhibitors of MMPs (TIMPs), serine proteases, such as the urokinase-type plasminogen activator (urokinase or uPA) and its plasminogen activator inhibitors, and the cysteine proteases such as the cathepsins, and their inhibitors the cystatins. $^{25}$

Cathepsins are a family of lysosomal proteases, which generally function optimally at acidic $\mathrm{pH}^{26}$ Prior studies have demonstrated correlations between tumor grade, increased invasive properties in vitro, and upregulation of cathepsins $\mathrm{B}, \mathrm{D}$, and $\mathrm{L} .{ }^{18,27-30}$ The predominant means of regulating the cysteine proteases is through their endogenous high affinity reversible inhibitors of the cystatin superfamily. Cystatins are divided into three types: the type 1 which lack a secretory signal peptide (cystatins A and B), the type 2 secreted cystatins (C, D, E/M, F, S, SN, and SA), and the type 3 multidomain cystatins (kininogens). ${ }^{31}$ It has been proposed that an imbalance between cysteine proteases and their specific inhibitors occur in the area of tumor cell invasion, because of an increase in cathepsin B and L activity and/or a decrease in expression of cysteine protease inhibitors such as the cystatins.

Cystatin E/M (or CST6, referring to the gene) is a potent inhibitor of cathepsin $\mathrm{B}, \mathrm{L}, \mathrm{H}$, and $\mathrm{V}^{31-34}$ Cystatin $\mathrm{E} / \mathrm{M}$ expression is frequently downregulated in breast cancers and ectopic expression of cystatin E/M in a breast cancer cell line reduced cell proliferation, migration, matrigel invasion, and adhesion. ${ }^{34}$ Orthotopic implantation of breast cancer cells ectopically expressing cystatin $\mathrm{E} / \mathrm{M}$ into the mammary fat pad of SCID mice resulted in marked delay of primary tumor growth and reduction in metastatic burden compared with implanted cells not expressing cystatin E/M. ${ }^{35}$ We recently showed that CST6 was frequently targeted for aberrant promoter hypermethylation in glioma cell lines and primary brain tumors and that cystatin E/M expression suppressed glioma cell growth. ${ }^{10}$

In the present paper, we sought to better understand the pattern of CST6 expression in non-neoplastic brain tissue, which has not been previously reported. We also examined the frequency of epigenetic silencing of CST6 in a larger and more diverse panel of primary adult and pediatric brain tumors, neural stem cells, and a tumor initiating cell line using immunohistochemistry and RT-PCR. CST6 expression 
was highly inversely correlated with CST6 promoter DNA methylation status using methylation-specific PCR (MSP), bisulfite genomic sequencing (BGS), and pyrosequencing with approximately $75 \%$ of tumors showing hypermethylation of CST6. Taken together, our results show that epigenetic silencing of CST6 is a very frequent and likely early event in gliomagenesis that may constitute a new therapeutic target.

\section{MATERIALS AND METHODS}

\section{Cell Lines, Tissue Culture, and Drug Treatments}

The glioblastoma cell lines U-87MG and T98G were purchased from the American Type Culture Collection and maintained in McCoy's 5-a medium (Mediatech) supplemented with L-glutamine and $10 \%$ fetal bovine serum (Hyclone). Normal human astrocytes (NHA) and human oligodendrocyte precursor cells (HOPC) were purchased from Lonza and ScienCell Research Laboratories, respectively, and cultured according to the manufacturer's instructions. Neural stem cells (SCP-23 and SCP- $27^{36}$ ) and glioma tumor initiating cells $\left(\mathrm{H} 1228^{37}\right)$ were maintained as undifferentiated cells under serum-free conditions or were induced to differentiate as described. Where indicated, cells were treated with 5-10 $\mu \mathrm{M} 5$-aza-2'-deoxycytidine (5-azadC) for 4 days (fresh drug was added every $24 \mathrm{~h}$ ), followed by a $24 \mathrm{~h}$ treatment with $100 \mathrm{nM}$ trichostatin A (TSA). In some cases, treatment with only one drug at the same concentration and time was also performed. All chemicals were purchased from Sigma. Primary cultures of pediatric brain tumors were established at the Miami Children's Hospital immediately after surgery by placing fresh tumor tissue in RPMI-1640. After rinsing with $1 \mathrm{X}$ PBS, tissue was minced with a sterile scalpel and scissors into small pieces $\left(0.5 \mathrm{~mm}^{3}\right)$ and digested with sterile medium containing trypsin $(0.05 \%)$, collagenase $(0.02 \%)$, DNase $(0.02 \%)$ and $0.53 \mathrm{mM}$ EDTA for $1 \mathrm{~h}$. Tumor cells were isolated on a histopaque 1077 gradient and cultured in RPMI medium containing 20\% fetal bovine serum, penicillin $(100 \mathrm{U} / \mathrm{ml})$, streptomycin $(100 \mu \mathrm{g} / \mathrm{ml})$ and L-glutamine $(1 \mathrm{mM}){ }^{38}$

\section{Tumor Specimens and Tissue Microarray}

Fresh-frozen and formalin-fixed paraffin-embedded tumors were provided by the Florida Center for Brain Tumor Research and the Miami Children's Hospital in accordance with policies of the Institutional Review Boards of the University of Florida and Miami Children's Hospital. All tumors were analyzed by a neuropathologist with expertise in human brain tumor diagnosis. Histopathological diagnoses were made according to definitions provided in the most recent 2007 WHO Classification of Tumors of the Central Nervous System. ${ }^{19}$ Diagnoses were also correlated with the results of two color fluorescence in situ hybridization (FISH) studies to detect losses of chromosomes $1 \mathrm{p}$ and $19 \mathrm{q}$ are described below. Specifics on the number of cases, pathologic type, grade, and other patient information are listed in Tables 1 and 2 .
Tissue samples were divided in two and one half was homogenized in Trizol (Invitrogen) for RNA purification and the other was used for DNA isolation using a standard proteinase $\mathrm{K}$, phenol/chloroform extraction method. Brain tissue blocks were obtained from the Molecular Tissue Bank of the Department of Pathology and the Human Brain Tumor Tissue Repository of the Evelyn F and William L McKnight Brain Institute, University of Florida. For each sample, 10-15 $5 \mu \mathrm{m}$-thick sections were cut and collected in a microcentrifuge tube. Samples were de-paraffinized with xylene three times, washed with 100 and $75 \%$ alcohol, air dried then digested with lysis buffer $(10 \mathrm{mM}$ Tris- $\mathrm{HCl}, 1 \mathrm{mM}$ EDTA, $1 \%$ SDS, $0.4 \mathrm{mg} / \mathrm{ml}$ proteinase $\mathrm{K}$, and $0.1 \mathrm{mg} / \mathrm{ml}$ RNAase A) at $50^{\circ} \mathrm{C}$ for $24 \mathrm{~h}$.

For the tissue microarray (TMA), hematoxylin and eosin (H\&E)-stained glass slides and paraffin-embedded blocks from human brain tumors or control tissues from brain tissue removed surgically for non-neoplastic conditions or from non-neurologically affected autopsy material were examined by two neuropathologists (JQ, ATY). Representative areas to be sampled were identified microscopically and circled on the H\&E slide. Each separate region was assigned its own number and letter, such that it could be uniquely identified given the case number, block designation, and tissue diagnosis. The circled $\mathrm{H} \& \mathrm{E}$ glass slide was matched with the corresponding region on the block and circled. Both circled glass slides and paraffin blocks were submitted to the TMA Laboratory of the Molecular Tissue Bank in the Department of Pathology and TMA slides constructed as described. ${ }^{39}$ Briefly, areas of interest were punched out from the donor block using a Beecher Tissue Microarrayer and placed into the receipt paraffin block following the pre-designed TMA grid map. The TMA block was then sectioned at $4-5 \mu \mathrm{m}$ and array-sections dried overnight.

\section{Reverse-Transcriptase (RT)-PCR, Bisulfite Genomic Sequencing, Methylation-Specific PCR, and Pyrosequencing}

RT-PCR, BGS, and MSP for CST6 expression and methylation analyses were carried out as described previously. ${ }^{10,40}$ For RT-PCR, amplification of $\beta$-actin served as a control for RNA integrity. Nestin and SOX2 RT-PCR primers were described in Widera et al. ${ }^{41}$ Following PCR, reaction products were resolved on $2 \%$ agarose gels and photographed using a BioRad gel documentation system. For pyrosequencing, a $245 \mathrm{bp}$ region was amplified from bisulfite modified genomic DNA. The primer sequences used are (UBF) 5'-GGTTT TTTGGGTTTTTTGAATTT- $3^{\prime}$ and (UBR) $5^{\prime}$-biotin-ACCAA AACCAAACCCAAC- $3^{\prime}$. Thermocycling conditions were: 1 cycle $\left(95^{\circ} \mathrm{C} 15 \mathrm{~min}\right) ; 50$ cycles $\left(94^{\circ} \mathrm{C} 30 \mathrm{~s} ; 55^{\circ} \mathrm{C} 45 \mathrm{~s} ; 72^{\circ} \mathrm{C}\right.$ $45 \mathrm{~s}$ ); and final extension at $72^{\circ} \mathrm{C}$ for $10 \mathrm{~min}$. PCR products were confirmed on agarose gels. Pyro Gold reagents (Biotage) were used to prepare samples for pyrosequencing following the manufacturer's instructions. Briefly, for each sample, 
Table 1 Summary of CST6 expression and methylation in adult normal and primary brain tumors from the TMA

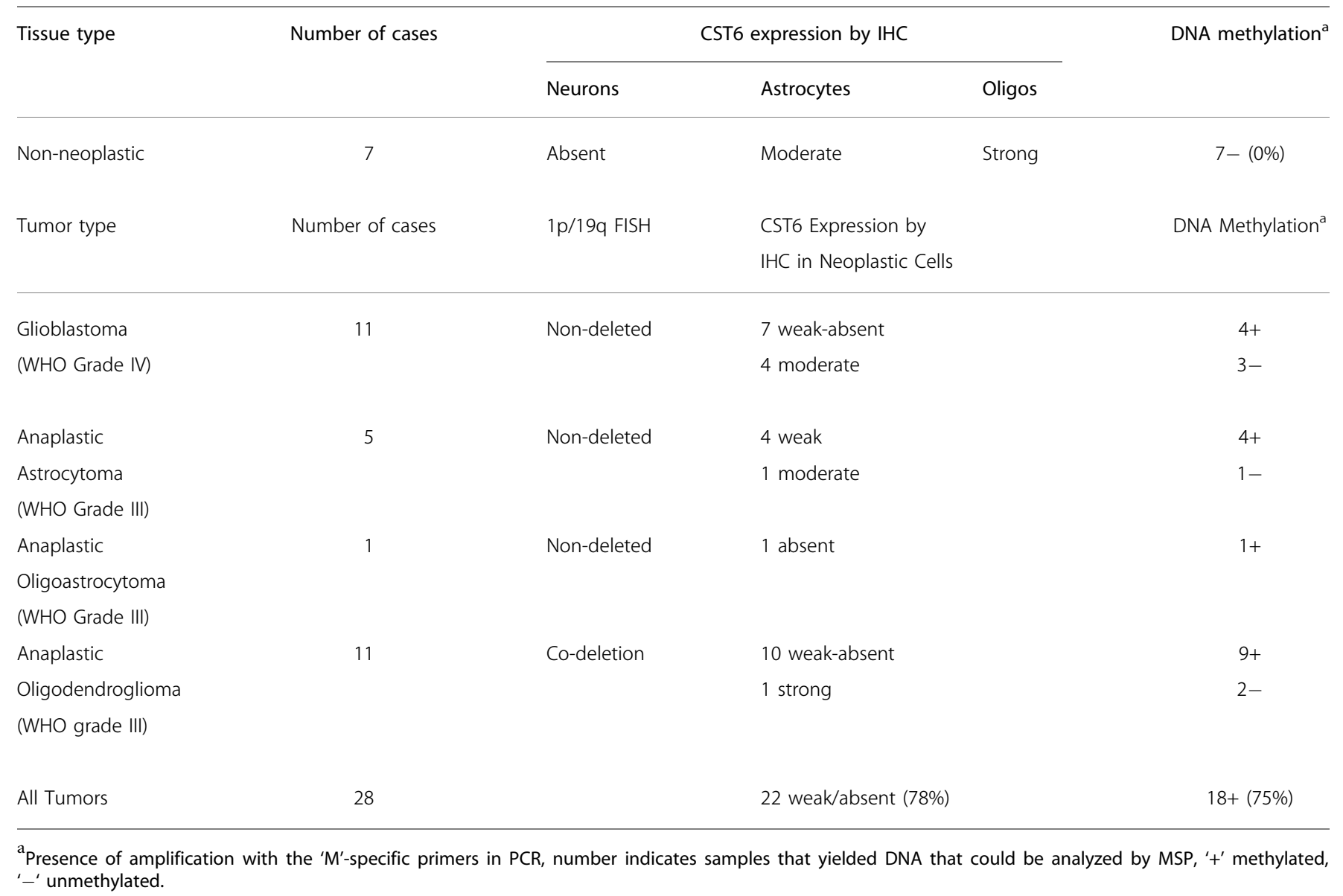

$10 \mu \mathrm{l}$ of PCR product was mixed with $2 \mu \mathrm{l}$ streptavidin sepharose HP (GE Healthcare), $40 \mu$ l binding buffer, and $28 \mu \mathrm{l}$ Milli-Q water, and incubated at room temperature for $10 \mathrm{~min}$ with shaking at 1400 r.p.m. The vacuum prep tool (Biotage) was used to isolate the sepharose bead-bound single-stranded PCR products. The attached DNAs were released into a PSQ HS 96-plate containing $12 \mu \mathrm{l}$ of $0.33 \mu \mathrm{M}$ sequencing primer in annealing buffer (Biotage). Pyrosequencing reactions were performed in a PyroMark MD System (Biotage). CpG methylation quantification was performed with Pyro Q-CpG ${ }^{\mathrm{TM}}$ 1.0.9 software (Biotage). The sequencing primer is $5^{\prime}$-GGTTTTGAGGGTTT- $3^{\prime}$. The dispensed sequence is: GTCGTATCGCTATGTATCGCTATAGTCTGTCAG.

\section{Immunohistochemistry (IHC) and Immunofluorescence}

TMA slides were deparaffinized, rehydrated, and processed for antigen retrieval by steaming in citrate buffer $(10 \mathrm{mM}$ sodium citrate $/ 0.05 \%$. Tween $20, \mathrm{pH} 6.0$ ) for $20 \mathrm{~min}$. After blocking with $5 \%$ BSA in PBS for $30 \mathrm{~min}$, slides were incubated with biotinylated goat anti-human cystatin E/M antibody (R\&D Systems; working concentration of $10 \mu \mathrm{g} / \mathrm{ml}$ ) at $4{ }^{\circ} \mathrm{C}$ for $24 \mathrm{~h}$. Following three washes with $0.2 \%$ Tween 20 in PBS, four drops of streptavidin-conjugated horseradish peroxidase solution (Kirkegarrd and Perry) were layered on the sections for $30 \mathrm{~min}$. Sections were washed again and DAB substrate (Vector Laboratories) was applied according to the manufacturer's directions. After this, sections were counterstained with hematoxylin. Control staining was carried out using the same procedure, except cystatin E/M antibody was substituted with biotinylated goat anti-rabbit IgG (KPL). Stained sections were observed using a Zeiss Axioplan 2 microscope and photomicrographs taken using a CCD camera. For the NHA immunofluorescence staining, approximately $1 \times 10^{5}$ cells were plated on glass cover slips, fixed in cold acetone, and air dried. Blocking was done by incubating cells with horse serum for $1 \mathrm{~h}$ at RT. After removing the serum, cells were incubated in goat anti-human cystatin E/M (R\&D Systems; 1:10) or rabbit anti-GFAP antibody (Shandon Immunon; $1: 10$ ) at $4{ }^{\circ} \mathrm{C}$ overnight. After washing with PBS three times, cells were incubated with donkey anti-rabbit (AlexaFluor 488; Molecular Probes; 1:500) or donkey anti-goat (AlexaFluor 594; Molecular Probes; 1:500) secondary antibodies in a dark environment for $2 \mathrm{~h}$ at RT. Cells were washed with PBS then nuclei were stained with DAPI. Cover slips were mounted onto glass slides with DAPI VectorShield mounting medium (Vector Labs), and photographed using a Nikon Eclipse TE-2000E fluorescence microscope with a CCD camera. 
Table 2 Summary of CST6 expression and methylation in pediatric brain tumor primary cell lines

\begin{tabular}{lcccc}
\hline $\begin{array}{l}\text { Tumor type/ } \\
\text { sample ID }\end{array}$ & Age & Sex & Expression $^{\text {a }}$ & $\begin{array}{c}\text { DNA } \\
\text { methylation }^{b}\end{array}$ \\
\hline Glioma & & & & \\
106 G (grade II) & 15 & F & - & + \\
$143 G$ (grade II) & 12 & F & - & - \\
150 G (grade III) & 12 & M & - & + \\
$157 G$ (grade II) & 15 & M & - & + \\
\end{tabular}

Ependymoma

$147 \mathrm{E}$

$168 \mathrm{E}$

$169 \mathrm{E}$

Pilocytic astrocytoma

93PA

101PA

$122 \mathrm{PA}$

129PA

$134 \mathrm{PA}$

Totals

$12 / 12(100 \%)$

$8 / 12(66 \%)$

${ }^{\mathrm{a}}$ Reduced or absent in untreated cells and upregulated by 5 -azadC treatment.

b Presence of amplification with the ' $M$ '-specific primers in $\mathrm{PCR}$, ' \pm ' weak but higher than normals.

\section{Analysis of Chromosomes $1 p$ and 19q by Fluorescence} In Situ Hybridization

Dual color FISH was performed on formalin-fixed paraffin sections of glioma specimens and normal brain tissue represented on the TMA described above. Commercially available probe sets (Vysis) were used according to standard procedures as specified by the vendor. Briefly, tissue sections on the TMA and control sections for each probe set were baked overnight at $60^{\circ} \mathrm{C}$ then deparaffinized through xylenes and alcohols. Following rehydration, sections underwent protease digestion (pepsin), followed by incubation with SpectumOrange ${ }^{\mathrm{TM}}$-labeled probe sets specific for the following chromosome regions: $1 \mathrm{p} 36$ and $19 \mathrm{q} 13$. SpectumGreen ${ }^{\mathrm{TM}}$ labeled control probes included sequences covering the 1q25 and 19 p 13 regions. Slides were rinsed two times for $2 \mathrm{~min}$ in post-hybridization buffers at $72^{\circ} \mathrm{C}$ (first buffer: $0.4 \times \mathrm{SSC} /$ $0.3 \%$ NP-40; second buffer: $2 \times$ SSC/0.1\% NP-40), allowed to come to room temperature, then rinsed with distilled water. Sections were then placed in the dark and allowed to air-dry. The TMA and all controls were examined an interpreted by a pathologist (ATY) experienced in the interpretation of FISH studies under $\times 100$ oil immersion using a Leitz Dialux ES fluorescence microscope (Wetzlar, Germany).

\section{Scratch Wound and Cell Invasion Assays}

For the scratch wound assay, $1.5 \times 10^{5}$ T98G cells were transfected with empty vector (pcDNA3.1, Invitrogen) or expression vector containing the full-length human cystatin $\mathrm{E} / \mathrm{M}$ open reading frame (pcDNA3-CST6) using LT1 according to the manufacturer's instructions (Mirus). ${ }^{10}$ After $48 \mathrm{~h}$, monolayers were scratched with a sterile P1000 tip, washed two times with $1 \times$ PBS, fresh media applied, and the cells photographed over the following $24 \mathrm{~h}$. For the cell invasion assay, T98G and U-87MG cells were transfected as for the scratch wound assay, then $1 \times 10^{5}$ transfected cells were plated in quadruplicate into wells precoated with $1 \times$ basement membrane extract using the Cultrex BME Cell Invasion Assay kit according to the manufacturer's protocol (Trevigen). Cells were plated in serum-free media in the top chamber and complete media with $10 \%$ serum was added to the lower chamber as chemoattractant. After $24 \mathrm{~h}$ cells migrating through the membrane to the underside of the filter were quantitated upon addition of Calcein AM solution and measuring fluorescence at $485 \mathrm{~nm}$ excitation/520 nm emission using a PolarStar multifunction plate reader (BMG LabTech).

\section{RESULTS \\ CST6 Expression and DNA Methylation Status in Non-Neoplastic Brain Tissues and Cells}

In our previous work, we identified CST6 as a gene frequently silenced by aberrant promoter hypermethylation in established glioma cell lines and a small group of primary uncultured adult brain tumors. ${ }^{10}$ Although much work has been done analyzing cystatin E/M expression and function in the context of breast cancer, ${ }^{42}$ little is known about its expression patterns in brain tissue. We therefore sought to examine cystatin $\mathrm{E} / \mathrm{M}$ expression patterns in non-neoplastic brain tissue using immunostaining. We established a tissue microarray (TMA) containing seven control brain tissue samples. TMA slides were stained for cystatin $\mathrm{E} / \mathrm{M}$ and representative results are shown in Figures $1 \mathrm{a}$ and $\mathrm{b}$ and all results are summarized in Table 1. Interestingly, cystatin E/M was highly expressed in oligodendrocyte-like cells (Figures 1a and b), moderately expressed in most astrocyte-like cells (Figures 1a, $c$ and d), but not expressed in neurons (Figure 1a). Given that astrocytes are not always readily identifiable by routine morphology in normal brain tissue, we examined cystatin E/M expression in normal cultured human astrocytes (NHA). NHA are a non-transformed relatively pure population of astrocytes that proliferate slowly for approximately 10 passages then undergo senescence (data not shown). We cultured NHA on glass cover slips, fixed, and stained them with both cystatin E/M and GFAP antibodies. GFAP is an established marker for astrocytes. This experiment demonstrated that the majority of cells $(>90 \%)$ were astrocytes, as shown by positive GFAP staining, and all GFAPpositive cells also stained positive for cystatin E/M. Cystatin $\mathrm{E} / \mathrm{M}$ staining was largely diffuse in the cytoplasm and in 


\section{Case \#32 normal cortex Case \#29 normal white matter}
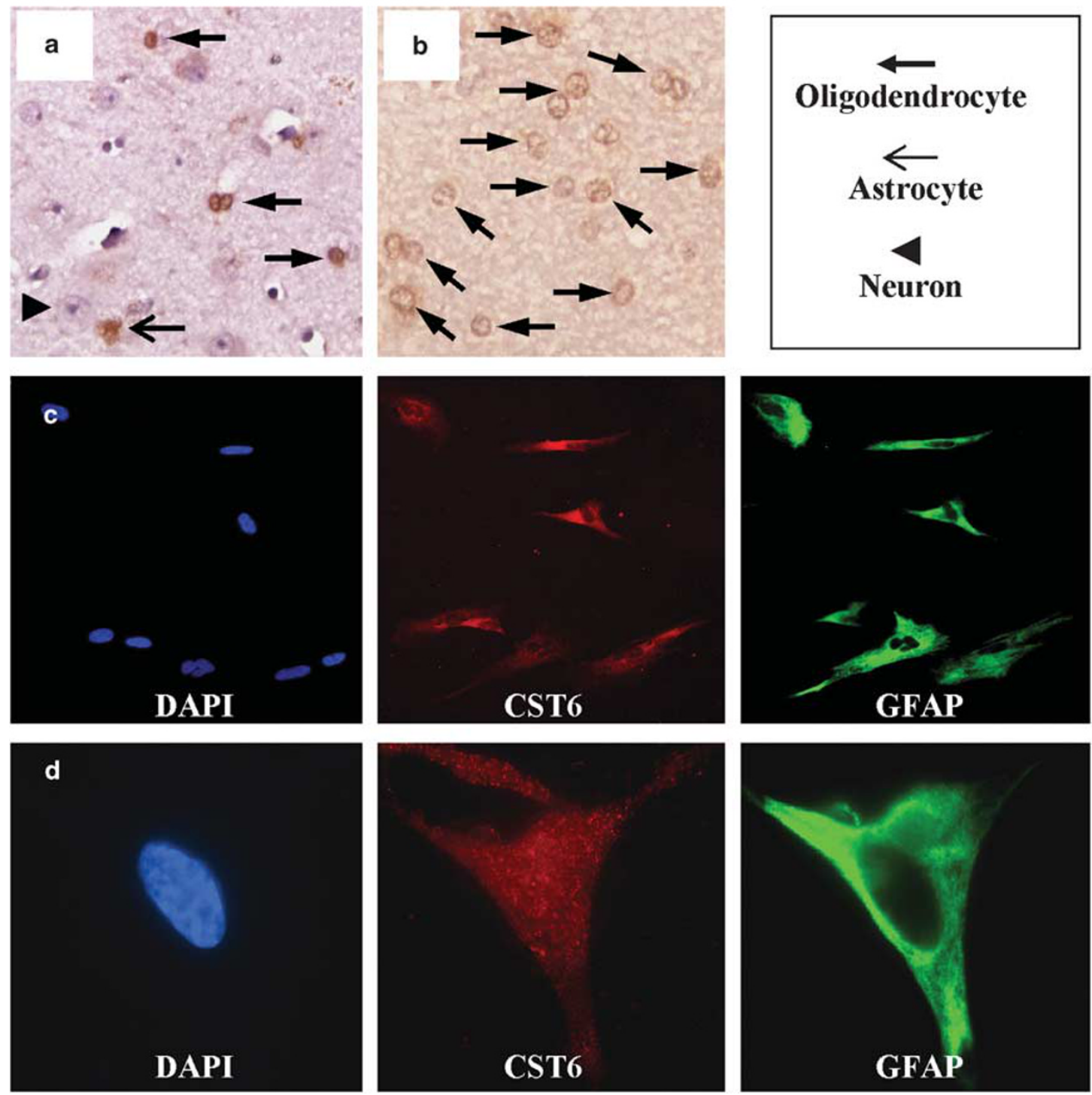

Figure 1 Localization of cystatin E/M expressing cells in non-neoplastic control brain tissue. (a, b) Immunohistochemical detection of cystatin E/M in normal cortex (a) and white matter (b) from two representative cases in the TMA. Brown color indicates cystatin E/M expression, which is undetectable in neurons (arrowheads), moderately expressed in many but not all astrocytes (open arrows), and highly expressed in oligodendrocytes (closed arrows). (c) Immunofluorescence staining of cultured normal human astrocytes (NHA) for cystatin E/M expression. Co-immunostaining of NHA for cystatin E/M, GFAP (a marker of astrocytes), and DAPI (to visualize nuclei). (d) Higher power image of a representative NHA. Images in (a-c) are taken at $20 \times$ magnification and in part (d) at $60 \times$ magnification.

small granular structures (Figures $1 \mathrm{c}$ and $\mathrm{d}$ ). In addition, some cells showed positive cystatin E/M staining in the nucleus, the significance of which is unknown.

Having established the cell types in the brain that express cystatin E/M, we next examined the DNA methylation status of the CST6 promoter CpG island using BGS (Figure 2a). Normal brain tissue was dissected into white matter and cortex and subjected to BGS analysis. BGS allows for determination of the DNA methylation status of all CpG sites between two PCR primers following treatment of genomic DNA with sodium bisulfite. ${ }^{43}$ This study revealed that the CST6 promoter was hypomethylated in normal brain tissue
(4-6\% of all CpG sites methylated, Figure 2b) demonstrating that CST6 promoter hypermethylation is not a feature of normal brain and that neurons, despite their lack of expression, do not contain methylated CST6 promoter alleles. We next examined CST6 promoter methylation in NHA and human oligodendrocyte precursor cells (HOPC). HOPC are a bipotential progenitor cell line that can be induced to differentiate into astrocytes or oligodendrocytes. ${ }^{44}$ Both NHA and HOPC cells contained very low levels of DNA methylation at the CST6 promoter region (10\%, Figure 2b) confirming that CST6 methylation is limited to no more than $10 \%$ in non-neoplastic cells of the brain. Sporadic DNA 
methylation was observed within the $53 \mathrm{CpG}$ sites examined in the CST6 CpG island in normal brain. Most methylated CpGs were downstream of the transcription start site. NHA and HOPC were slightly more methylated than normal brain downstream of the transcription start and only one $\mathrm{CpG}$ at the extreme $5^{\prime}$ end of the BGS region was notably more methylated in these cultured cells compared with primary brain tissue (Figure 2b). Nevertheless, CST6 promoter methylation levels were extremely low in all normal tissues and cultured cells consistent and compatible with CST6 expression.

\section{CST6 Expression and DNA Methylation Status in Primary Brain Tumors}

We next examined cystatin $\mathrm{E} / \mathrm{M}$ expression in a panel of primary adult brain tumor tissues using the TMA. In addition to the normal tissues analyzed above, the TMA contained 11 glioblastomas (GBM, WHO Grade IV) that included one GBM with sarcomatous elements (ie, gliosarcoma), five anaplastic astrocytomas (AA, WHO grade III), one mixed anaplastic oligoastrocytoma (WHO Grade III), and 11 WHO grade III anaplastic oligodendrogliomas (AO). All cases studied in the TMA were analyzed for deletions of chromosomes $1 \mathrm{p}$ and $19 \mathrm{q}$ by FISH and these results are summarized in Table 1.

TMA slides were immunostained for cystatin E/M and scored independently by two neuropathologists. Representative staining for five tumor cores is shown in Figure 3. In one GBM sample (Figure 3a) that also contained adjacent reactive brain tissue, cystatin $\mathrm{E} / \mathrm{M}$ was clearly expressed in the reactive astrocytes but not in tumor cells. The majority of the tumor cores, $78 \%$ overall, showed reduced or absent expression of cystatin E/M (Table 1). Interestingly, most of the anaplastic oligodendrogliomas exhibited weak or absent cystatin E/M reactivity (Figure 3e), which is in marked contrast to the high levels of cystatin $\mathrm{E} / \mathrm{M}$ observed in control white matter oligodendrocytes (Figure 1). This result suggests a particularly important function for cystatin $\mathrm{E} / \mathrm{M}$ in oligodendrocytes and shows that reduced or absent cystatin $\mathrm{E} / \mathrm{M}$ expression is common in a diverse group of primary gliomas.

To examine the correlation between CST6 expression and promoter hypermethylation, we employed a combination of MSP and pyrosequencing. Both methods rely on bisulfiteconverted DNA. MSP provides a semiquantitative measure of DNA methylation levels of several CpG sites contained within a PCR primer-binding site, ${ }^{45}$ whereas pyrosequencing is a highly quantitative technique for assessing DNA methylation levels at select CPG sites, usually limited to a 50-100 bp region. ${ }^{46}$ DNA was prepared from the majority of tissues present in our TMA and subsequently treated with sodium bisulfite. Some tissues did not yield DNA in sufficient quantity or quality to be further analyzed. MSP was run on all samples and tissues were scored positive for DNA methylation if a band was present in the methylated allele-specific PCR(Table 1, Figure 4a). Twenty-two samples were also analyzed by pyrosequencing as additional confirmation and to determine absolute levels of DNA methylation (Figures $4 \mathrm{~b}$ and $\mathrm{c}$ ). Representative MSP and BGS results are shown in Figures $4 \mathrm{a}$ and $\mathrm{b}$ and the overall DNA methylation level at $5 \mathrm{CpG}$ sites (Figure 2a) for all of the samples pyrosequenced is shown in Figure 4c. In general, there was tight agreement between the MSP and the pyrosequencing results and an excellent inverse correlation between cystatin $\mathrm{E} / \mathrm{M}$ expression as judged by IHC and levels of DNA methylation (by pyrosequencing/MSP, Figure 4, Table 1). In rare cases, such as AO tumor C6, we found no CST6 promoter methylation by MSP or pyrosequencing but cystatin E/M expression by IHC was clearly reduced. In this case, CST6 may be silenced by other forms of epigenetic modification, such as histone deacetylation, or the gene may be mutated. Consistent with the BGS analysis in Figure 2, all normal tissues were hypomethylated by pyrosequencing analysis ( $\sim 5 \%$ methylation, Figures $4 \mathrm{~b}$ and c). Overall, $75 \%$ of the tumor tissues displayed CST6 promoter hypermethylation, in close agreement with the IHC data (Table 1), indicating that epigenetic silencing of CST6 is a very frequent event in primary brain tumors.

\section{Expression and DNA Methylation Status of CST6 in Normal Neural Stem Cells and Glioma Tumor-Initiating Cells Before and After Differentiation}

Neural stem cells are multipotent progenitor cells capable of giving rise to neurons, astrocytes, and oligodendrocytes. Cells resembling cultured neural stem cells (NSC) are present in adult brain, particularly in the subventricular zone. ${ }^{36,47}$ Interesting recent findings suggest that a rare population of transformed stem cell-like cells (tumor initiating cells, (TIC)) may give rise to primary brain tumors. ${ }^{37}$ The origins of TICs are unknown but they may arise from a transformed normal NSC or from a transformed and dedifferentiated astrocyte or oligodendrocyte. A characteristic feature of TICs particularly relevant to the current study is that they recapitulate the highly invasive phenotype of primary brain tumors, a feature not mimicked by most established cell lines like T98G or U-87MG cells cultured in serum-containing conditions. ${ }^{37,48}$ We examined two fetal-derived human NSCs maintained under non-differentiating conditions (serum-free media with EGF and bFGF) ${ }^{36}$ for CST6 expression and promoter region DNA methylation. Interestingly, both NSC lines, SCP23 and SCP27, expressed moderate to high levels of CST6 by semiquantitative RT-PCR (Figure 5a). The reason for the different CST6 levels between the two NSC lines in not known but could be related to their time in culture, region of the brain from which they were isolated, or developmental stage. In stark contrast, a well-characterized and highly invasive glioma TIC line, H1228, expressed no detectable CST6, even at high PCR cycle numbers (Figure $5 \mathrm{a}$ and data not shown). As an initial test of whether the CST6 gene was epigenetically silenced in $\mathrm{H} 1228$ cells, we treated it with $10 \mu \mathrm{M}$ 5-azadC 
a
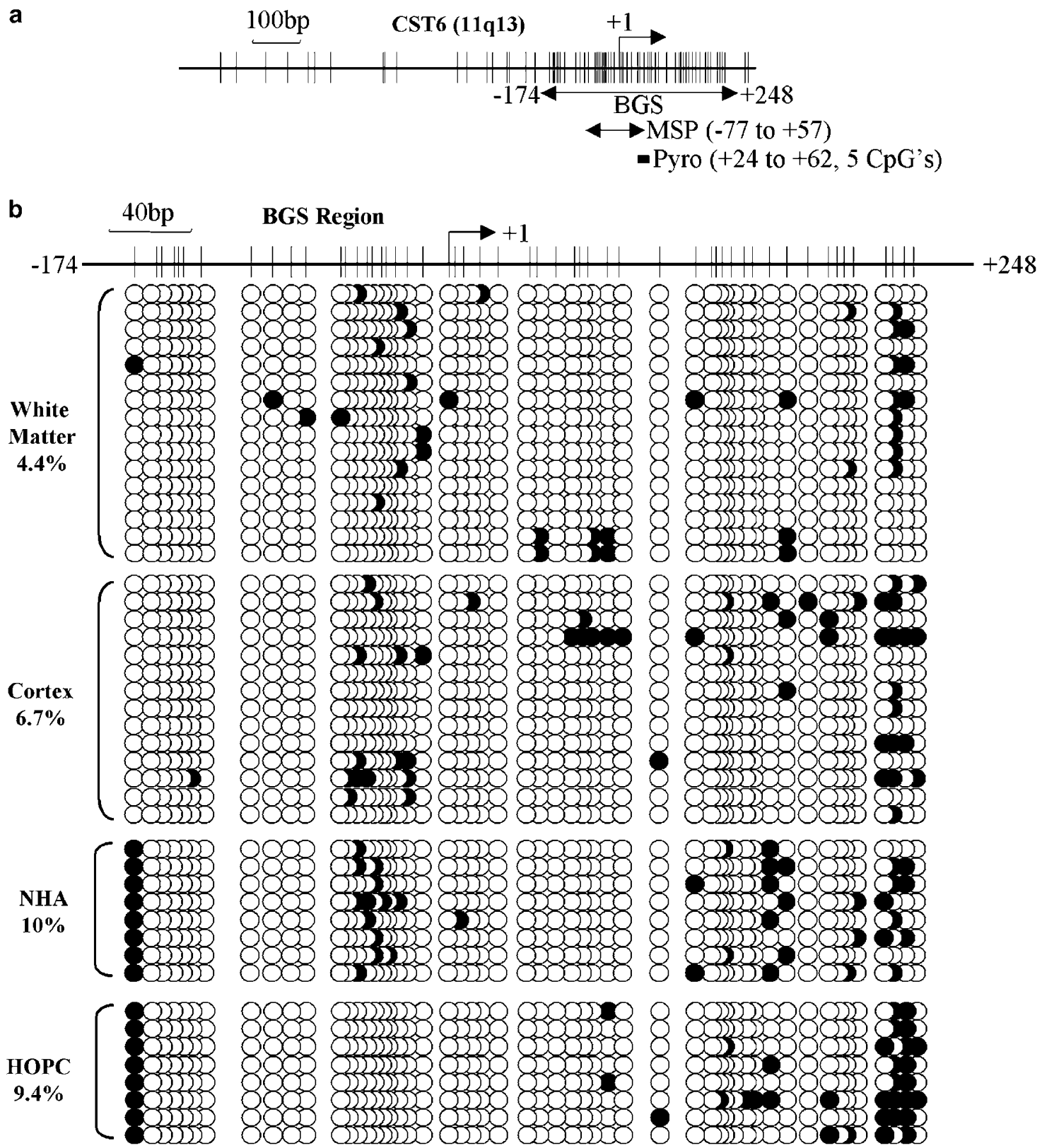

Figure 2 Bisulfite genomic sequencing (BGS) DNA methylation analysis of the CST6 promoter in normal brain and cultured cells. (a) Schematic of the CST6 promoter region with the vertical tick marks indicating CpG sites and the bent arrow $(+1)$ denoting the transcription start site defined using NCBI Map Viewer. Below this, the boundary of the regions analyzed by BGS, MSP, and pyrosequencing throughout the paper are shown with numbering relative to the transcription start site. (b) BGS analysis of normal white matter and cortex tissues, NHA, and human oligodendrocyte precursor cells (HOPC). The total percent methylation for all clones is indicated at the left. The BGS region shown in part (a) is expanded at the top. Each row of circles (representing CpG sites) corresponds to one sequenced clone. Open and filled circles represent unmethylated and methylated CpGs, respectively.

for 10 days. The cells showed little drug toxicity from the 5-azadC treatment (data not shown) and CST6 was re-expressed (Figure 5a), suggesting that the gene is subject to DNA hypermethylation in this line. RT-PCR amplification of pluripotency genes Nestin and SOX2 confirmed the undifferentiated phenotype of NSC and TIC under our culture conditions, in contrast to the serum-cultured established glioma cell line, T98G, which did not express either of these markers. We next examined the DNA methylation patterns of these three lines by BGS. Consistent with CST6 expression levels by RT-PCR, the NSC lines SCP23 and SCP27 contained little CST6 methylation $(<10 \%)$ whereas the glioma TIC line, H1228, was hypermethylated at the CST6 promoter $(\sim 50 \%)$ at a level consistent with most of the primary uncultured brain tumor samples analyzed in the TMA by pyrosequencing. Finally, we examined 


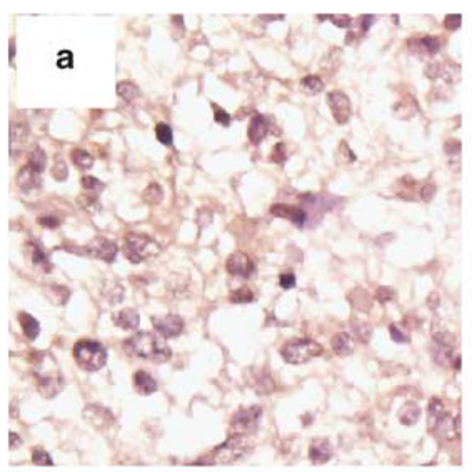

GBM
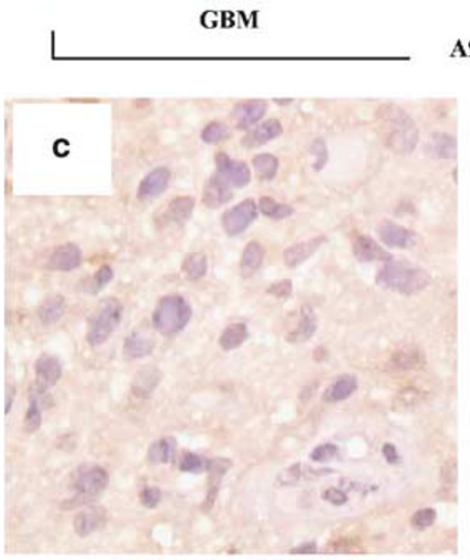

A5 small cell GBM

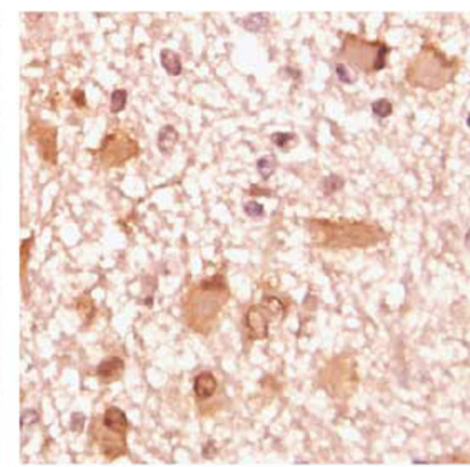

Adjacent reactive

A9

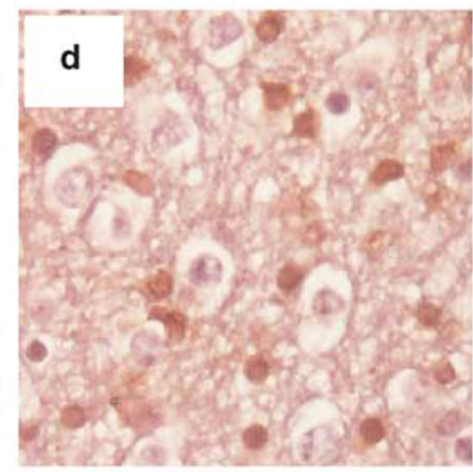

G9 AO

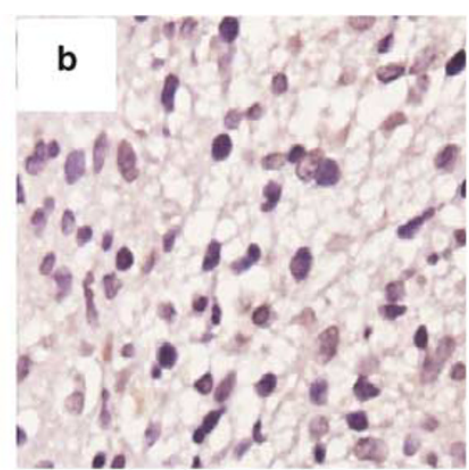

B7 GBM

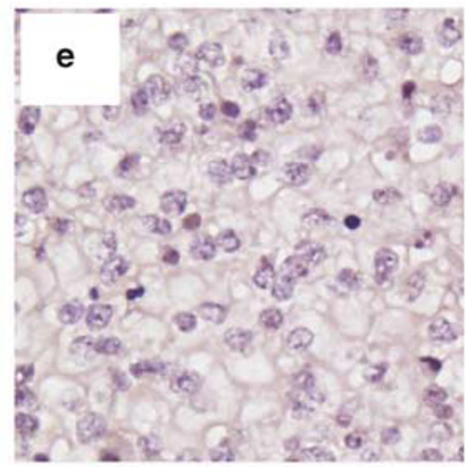

C11 AO

Figure 3 Representative immunohistochemical staining for cystatin E/M expression in primary brain tumors from the TMA. (a) Two regions from one TMA core showing predominantly tumor (GBM, left panel) and adjacent reactive-appearing brain tissue (right panel). Only the reactive tissue stains positive for cystatin E/M. Cystatin E/M expression in (b, c) glioblastoma (GBM) and (d, e) two anaplastic oligodendrogliomas (AO). Tumor cells show little or no cystatin E/M reactivity.

expression of CST6 upon differentiation of NSC and TIC with serum and/or retinoic acid. ${ }^{36,37}$ Interestingly, CST6 was markedly upregulated in both NSC lines ( 50-300 fold), whereas the TIC H1228 was completely blocked for differentiation-induced CST6 upregulation (Figure 5c and data not shown). Taken together, these results demonstrate that CST6 is expressed in normal NSC in an undifferentiated state but is silenced in a highly invasive glioma TIC line. As such, CST6 silencing may represent a very early event in the process of gliomagenesis.

\section{Frequent CST6 Silencing by Multiple Epigenetic Mechanisms in Primary Pediatric Brain Tumors}

The CST6 promoter was hypermethylated in approximately $70 \%$ of the primary adult brain tumors we examined and invasiveness is a hallmark of all of these tumor types. ${ }^{18}$ Although the prognosis of some pediatric patients with brain tumors such as pilocytic astrocytoma is generally good due to its rather focal character, other pediatric gliomas are infiltrative. ${ }^{49}$ We therefore determined CST6 expression and promoter methylation status in a panel of 12 primary cell lines derived from patients ranging in age from 1 to 15 years old. This panel includes four infiltrating astrocytomas (WHO Grade II-III), three ependymomas, and five pilocytic astrocytomas (WHO Grade I) (summarized in Table 2). DNA and RNA was prepared from early passage lines $(<10$ passages $)$ and used to assess CST6 expression by semiquantitative RT-PCR with or without treatment with a combination of 5 -azadC and TSA $(5 \mu \mathrm{M} 5$-azadC for 3 days followed by a final $24 \mathrm{~h}$ treatment with $100 \mathrm{nM}$ TSA). Results for all cell lines are summarized in Table 2 and a representative subset of each tumor type is shown in Figure 6a. These data clearly reveal absent or low-level expression of CST6 in all 12 cell lines, regardless of tumor type. In addition, in all cases CST6 expression was upregulated upon treatment with 5 -azadC and TSA ('A $+\mathrm{T}$ ' lanes in Figure 6a), suggesting that epigenetic modifications are mediating repression of the CST6 gene.

MSP analysis of the CST6 promoter in the pediatric lines confirmed promoter hypermethylation in the majority of cases (66\% overall, Table 2, Figure 6b). One notable exception was the pilocytic astrocytomas, which showed very low or absent expression of CST6, but also demonstrated little CST6 promoter hypermethylation, suggesting that other epigenetic modifications may repress CST6 in these tumors. To study this further, a subset of the pediatric brain tumor cell lines derived from two tumor types were treated singly with $5 \mu \mathrm{M} 5$-azadC for 3 days or $100 \mathrm{nM}$ TSA for $24 \mathrm{~h}$. Cell 
a

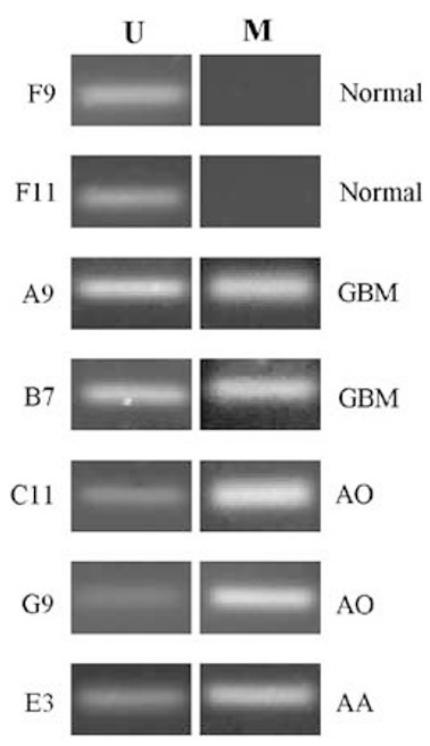

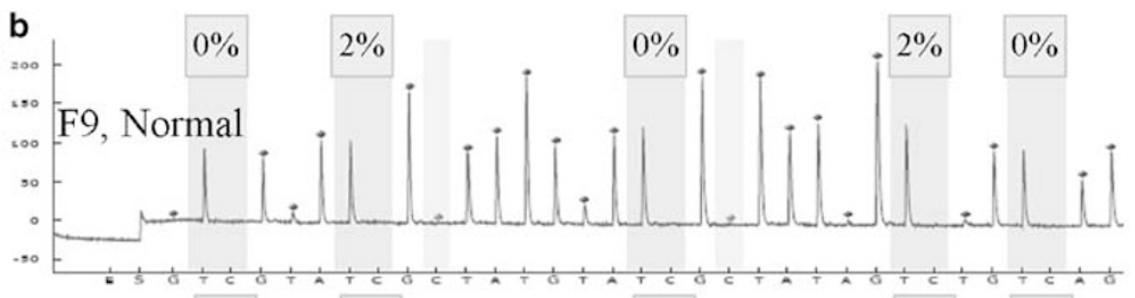
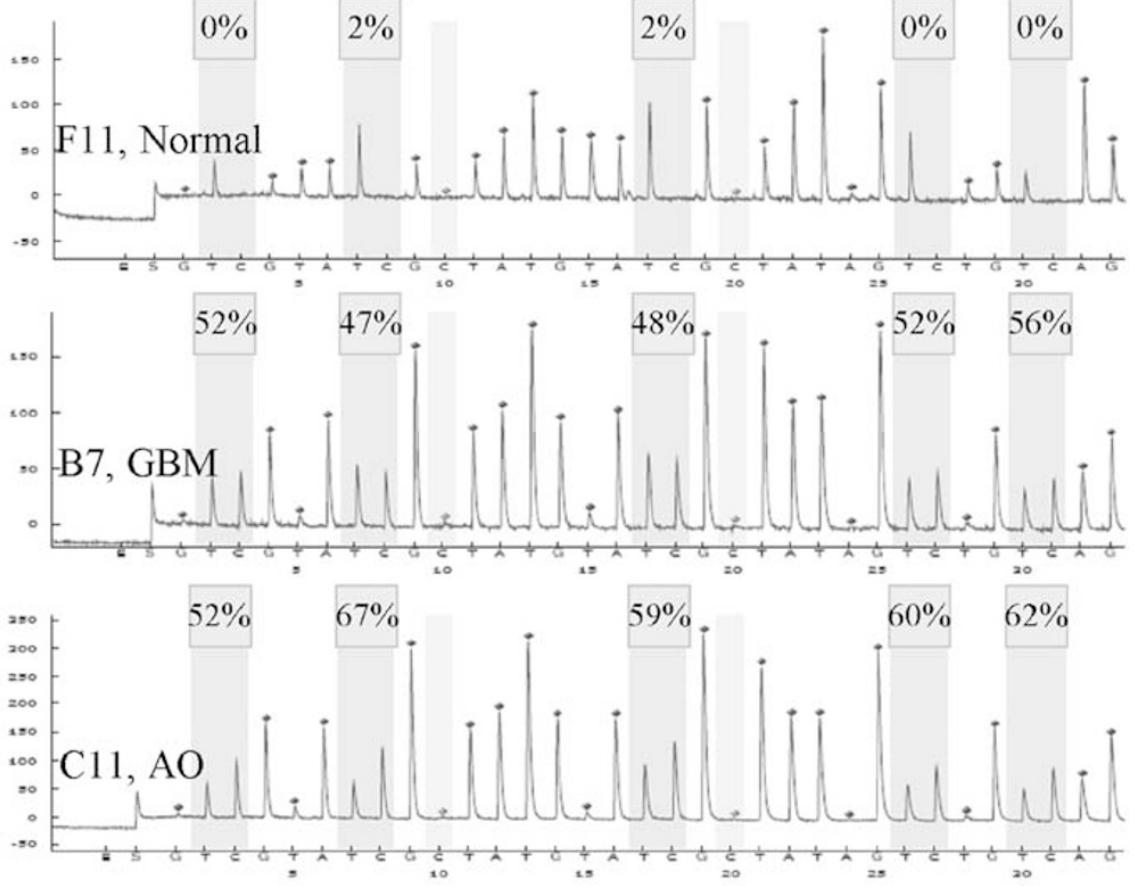

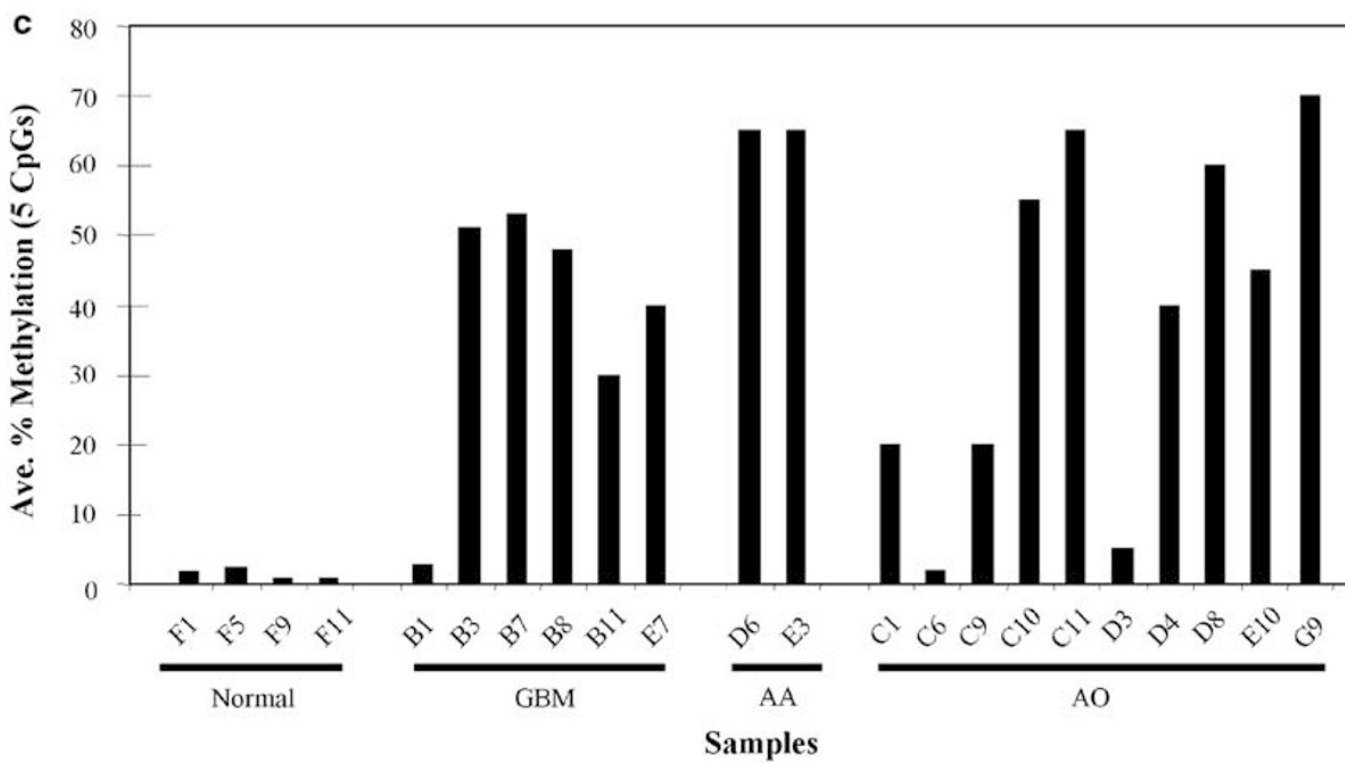

Figure 4 MSP and pyrosequencing DNA methylation analysis of normal and tumor tissues from the TMA. (a) Representative MSP results for two normal and five primary brain tumor samples from the TMA. ' $U$ ' and ' $\mathrm{M}$ ' represent PCR amplification with primers specific for unmethylated and methylated CST6 promoter, respectively (see also Figure 2a). (b) Bisulfite pyrosequencing DNA methylation analysis for two normal and two tumor tissues from the TMA. Representative pyrograms are shown for each sample with the percent methylation at each of five CpG sites given above its location in the sequence (see Figure 2a for the region analyzed by pyrosequencing). (c) Average percent methylation for the five CpG sites shown in part B for four non-neoplastic tissues and 18 tumor tissues derived from the TMA. These samples were also analyzed for cystatin E/M expression in the TMA by IHC. There was an excellent correlation between the MSP and pyrosequencing data as well as the presence of DNA hypermethylation ( $>20 \%)$ and reduced/absent cystatin E/M expression by IHC (Table 1). 

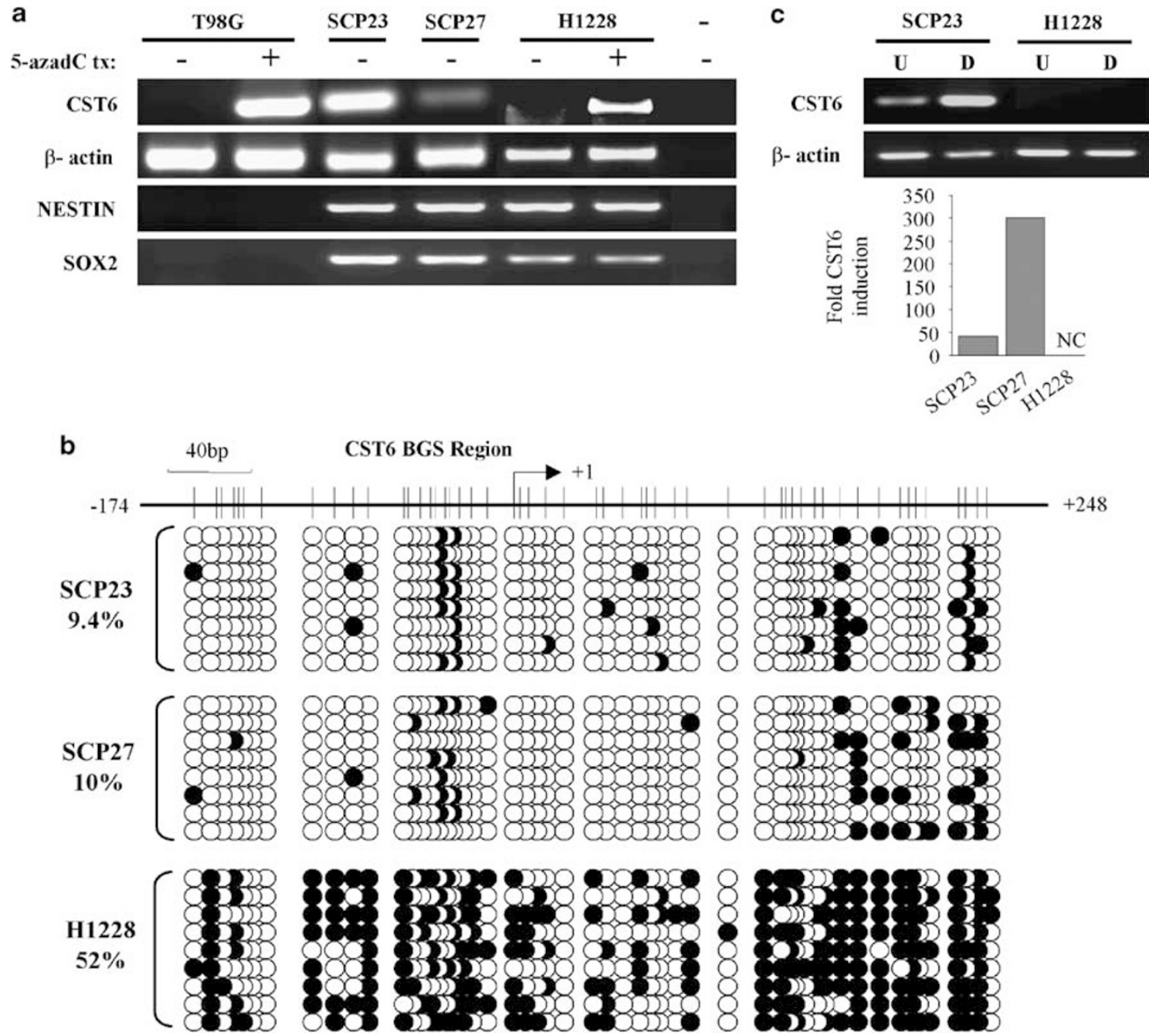

Figure 5 CST6 expression and methylation status in neural stem cells and glioma tumor initiating (tumor stem) cells. (a) Semi-quantitative RT-PCR analysis showing that CST6 is expressed at moderate to high levels in two neural stem cell lines (SCP-23 and SCP-27) cultured under non-differentiating conditions. In contrast, the glioma initiating line H1228 does not express CST6 but can be induced to re-express CST6 following treatment with $5 \mu \mathrm{M}$ 5-azadC for 10 days (' +' lane). Untreated and 5-azadC-treated T98G cells serve as negative and positive controls for CST6 expression, respectively. Expression of Nestin and SOX2 demonstrate the multipotent phenotype of normal stem cells and tumor initiating cells. Amplification of $\beta$-actin serves as a loading control. (b) CST6 BGS methylation analysis of neural stem cells and the tumor initiating line H1228. High-level methylation of the CST6 promoter in $\mathrm{H} 1228$ is consistent with the lack of CST6 expression in the absence of 5-azadC treatment. (c) RT-PCR analysis showing that CST6 expression is induced in neural stem cells following differentiation, whereas this upregulation is blocked in $\mathrm{H} 1228$ cells. The graph shows representative gel quantitations and is presented as the fold change in CST6 expression upon differentiation (relative to the undifferentiated cells). 'NC'-not calculated as no CST6 expression was detectable. ' $\mathrm{D}$ ' differentiated, ' $\mathrm{U}$ ' undifferentiated.

lines positive for CST6 promoter methylation by MSP showed CST6 gene reactivation largely only upon 5 -azadC treatment but not TSA treatment (Figure 6c, 106G). This is consistent with other studies showing that hypermethylated promoters are usually dominantly silenced by DNA methylation and not efficiently reactivated by TSA alone. ${ }^{50}$ In contrast, those lines that lacked significant CST6 methylation (101PA for example, Figure 6b) were reactivated by 5 -azadC or TSA treatment equally well, consistent with a lower level of DNA methylation and the possible contribution of other repressive epigenetic marks to CST6 silencing in this tumor type. We used BGS to define the degree of DNA hypermethylation at the CST6 promoter in a subset of the pediatric lines in greater detail (Figure 6d). In general, the results correlated well with the MSP and RT-PCR data. Line 106G had promoter methylation levels comparable to adultderived primary brain tumors and TSA treatment did not lead to CST6 reactivation in this sample (Figure 6c). In contrast, however, 101PA had lower levels of DNA methylation, higher basal levels of CST6 expression (without drug treatment, Figure 6a), and showed CST6 reactivation in the presence of TSA alone (Figure $6 \mathrm{c}$ ). Taken together, our analysis of pediatric primary brain tumors suggests that CST6 silencing by epigenetic mechanisms is quite common and 
occurs in lower grade tumors. This result also supports the idea that CST6 silencing may be an early event in gliomagenesis.

\section{Ectopic Expression of CST6 Reduces Glioma Cell Motility and Invasion In Vitro}

It has been well established that cystatin E/M modulates motility and invasion in vitro and in vivo in the context of breast cancers, where it is also frequently silenced by promoter hypermethylation; ${ }^{34,35,40}$ however, the role of cystatin $\mathrm{E} / \mathrm{M}$ in modulating these properties in glioma cells has not been investigated. We therefore cloned the full length CST6 open reading into an expression plasmid and transiently transfected T98G and U-87MG cells for $48 \mathrm{~h}$. The endogenous CST6 gene is epigenetically silenced in both of these lines ${ }^{10}$ but transfection results in re-expression of cystatin $\mathrm{E} / \mathrm{M}$ at levels comparable with those observed in a breast cancer cell line in which the endogenous CST6 gene is unmethylated and expressed (MDA-MB-231, Figure $7,{ }^{40}$ ). We next analyzed effects of cystatin E/M expression on T98G cell motility using a scratch wound assay. Empty vector and CST6 transfected T98G cells were grown to near confluence after transfection, the monolayer was wounded with a pipette tip, and the migration of cells into the open area monitored over $24 \mathrm{~h}$. Empty vector transfected T98G cells nearly filled in the open area after $24 \mathrm{~h}$ whereas the CST6 transfected cells did not (Figure 7a). U-87MG cells were not used in the scratch wound assay because they do not form a coherent monolayer (not shown). To directly address invasion, transfected cells were plated in a cell invasion assay to measure their ability to penetrate a reconstituted basement membrane overlaying a polycarbonate filter. Cells able to penetrate this ECM-like substrate migrate to the underside of the filter and are quantitated fluorimetrically. Consistent with the effects of cystatin E/M on cell motility, cell invasion was also markedly reduced in transfected U-87MG and T98G cells ( $\sim 50 \%$, Figure $7 \mathrm{~b}$ and data not shown). Therefore, our data demonstrate that ectopic expression of cystatin $\mathrm{E} / \mathrm{M}$ modulates both motility and invasion of glioma cells suggesting that epigenetic silencing of CST6 in primary brain tumors contributes to their highly invasive nature.

\section{DISCUSSION}

In the present paper, we have analyzed the expression and DNA methylation status of CST6 in normal and neoplastic brain tissues. Interestingly, cystatin E/M is highly and moderately expressed in oligodendrocytes and astrocytes, respectively, but there is no detectable expression in neurons. Consistent with this expression pattern and what has been reported by others for most $\mathrm{CpG}$ island containing gene promoters, the CST6 promoter region is hypomethylated in normal brain, normal astrocytes (NHA), and a non-transformed bipotential progenitor cell line (HOPC) that can give rise to astrocytes and oligodendrocytes. In contrast, cystatin $\mathrm{E} / \mathrm{M}$ expression is reduced or absent in the majority of adult primary brain tumors we examined and these tumors show high-level CST6 promoter methylation using three techniques, BGS, MSP, and pyrosequencing. We also examined CST6 expression in two neural stem cell lines and found that CST6 was expressed and hypomethylated in both and markedly upregulated upon differentiation. A well characterized tumor initiating (or tumor stem) cell line, however, did not express CST6, showed dense promoter hypermethylation, which was reversed upon 5-azadC treatment, and was completely blocked for differentiation-induced upregulation of CST6. These results suggest that CST6 silencing is an early event in gliomagenesis occurring in the cells responsible for initiating and supporting the growth of the bulk tumor. Pediatric primary brain tumors of diverse cellular origin and grade also demonstrated frequent CST6 downregulation and promoter methylation. Finally, we showed for the first time that ectopic expression of cystatin E/M in glioma lines in which the endogenous gene is epigenetically silenced reduced cell motility and invasion in vitro. Taken together these studies show that CST6 epigenetic silencing is a frequent and early event in the genesis of primary brain tumors. In addition, because of its frequency and occurrence in glioma TICs, but not normal neural stem cells, it may represent a new prognostic/diagnostic marker for astrocytic tumors and a novel tumor initiating cell therapeutic target.

Cystatin $\mathrm{E} / \mathrm{M}$ acts as a potent tight-binding reversible inhibitor of cathepsin B and it also inhibits the activity of cathepsins L, H, and V, papain, and legumain. ${ }^{31-33,51}$ Cystatin $\mathrm{E} / \mathrm{M}$ therefore has an inhibitor profile somewhat distinct from the other members of the type 2 secreted cystatins (cystatins C, D, S, SN, and SA). CST6 is also distinctive in its chromosomal location (located on chromosome 11q13; other type 2 cystatins plus two pseudogenes are located at 20q11.2) and existence of the protein in a glycosylated form at amino acid 108. Cystatin E/M shares only $26-34 \%$ identity with other type 2 cystatins and less than $30 \%$ identity with the type 1 family cystatins. ${ }^{33}$ CST6 mRNA is widely expressed in most human tissues and is highly enriched in rat brain. ${ }^{32,33}$ The specific role of cystatin E/M in normal growth and homeostasis of astrocytes and oligodendrocytes is unclear. The high level of cystatin E/M expression that we have observed in oligodendrocytes, which are non-motile cells in adult brain, is intriguing. Cystatin E/M may be secreted by oligodendrocytes into the brain parenchyma to regulate motility of other cells, such as astrocytes or microglia. Alternatively, cystatin E/M may have a novel intracellular role (cytoplasmic or nuclear) or a role in regulating neuronal activity. In support of the former possibility, cathepsin L (a target of cystatin E/M inhibition) exists in an alternative intracellular form that localizes to the nucleus and regulates transcription by cleavage of the transcription factor CDX/Cux. ${ }^{52}$ We noted significant levels of intracellular/ cytoplasmic cystatin E/M in NHA in our study and this appeared to be nuclear in some cells. Support for a possible role of cystatin $\mathrm{E} / \mathrm{M}$ in regulating neuronal activity stems 
a

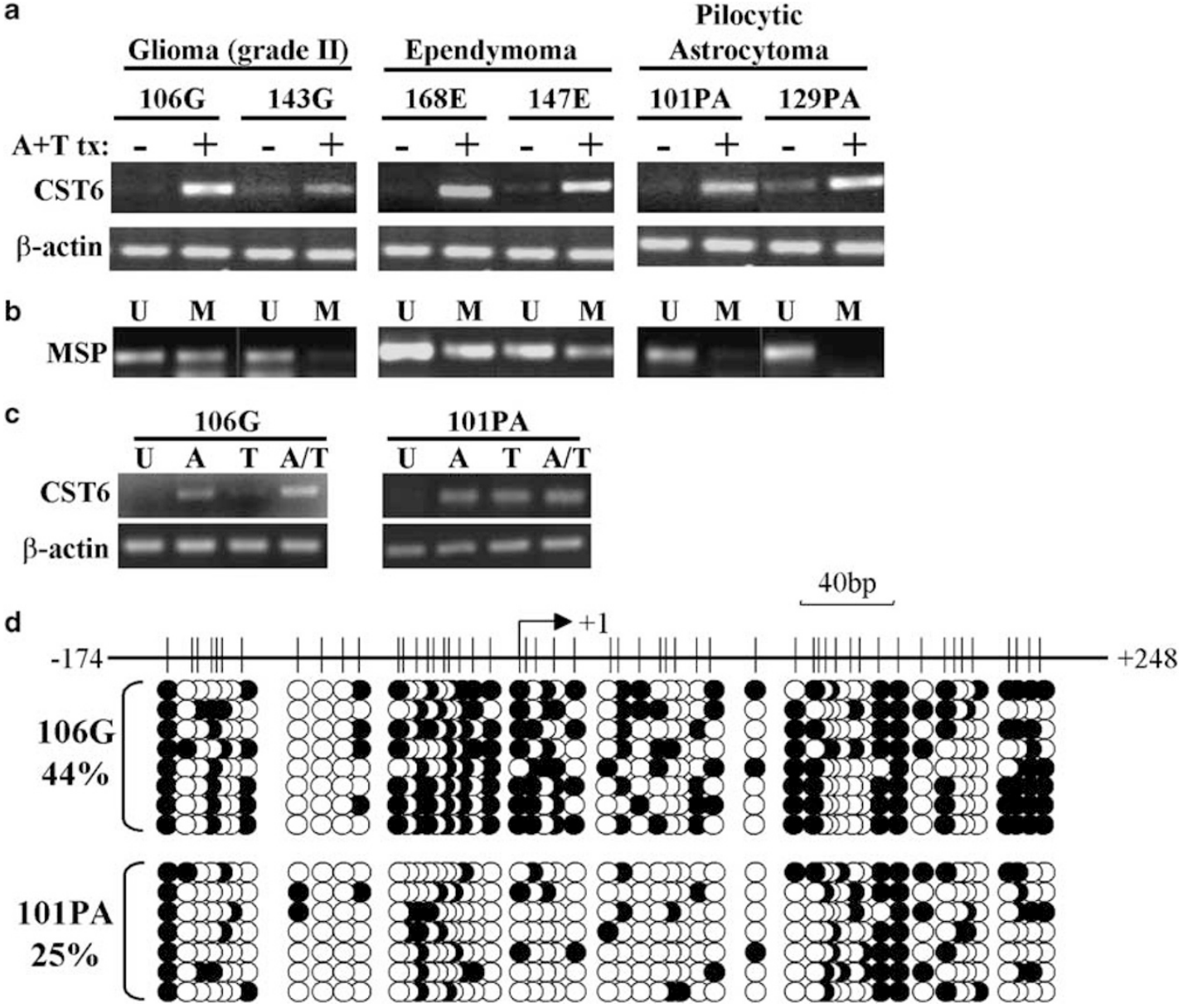

Figure 6 CST6 silencing and promoter hypermethylation is common in low and high grade pediatric primary brain tumor cultures. (a) Representative RTPCR analysis of CST6 expression in primary cell lines derived from different types of pediatric brain tumors cultured in the absence ('-') or presence (' + ') of 5 -azadC ( $5 \mu \mathrm{M}$ for 3 days) and TSA ( $100 \mathrm{nM}$ for final $24 \mathrm{~h}$, 'A + T' lanes). Amplification of $\beta$-actin serves as a loading control. (b) MSP DNA methylation analysis of the same group of tumors from part (a) showing that CST6 promoter hypermethylation is common and correlates with transcript inducibility by 5 -azadC and TSA. (c) CST6 expression by RT-PCR in cells treated singly with 5-azadC ('A') or TSA (' $T$ '). (d) BGS methylation analysis of select pediatric brain tumor cultures. G—glioma, PA—pilocytic astrocytoma.

from a recent paper demonstrating that cathepsins $\mathrm{B}$ and $\mathrm{L}$ function in the biosynthesis of neurotransmitters. ${ }^{53}$ These alternative roles for cystatin $\mathrm{E} / \mathrm{M}$ would require co-localization of cystatin $\mathrm{E} / \mathrm{M}$ and the cathepsin either intracellularly or at neuronal synapses so that cystatin E/M would have access to and be able to regulate cathepsin proteolytic activity.

Another unique feature of cystatin E/M compared with other members of the cystatin family is the high frequency with which it is targeted for epigenetic silencing in a variety of tumors. Cystatin E/M was initially characterized as a protein frequently downregulated in invasive breast cancers. $^{34,35}$ We were the first to show that CST6 silencing in breast cancer was due to promoter hypermethylation and that CST6 methylation was detectable in a preinvasive breast cancer lesion, ductal carcinoma in situ, at a significant frequency. ${ }^{40}$ This finding has also been supported by work from other laboratories. ${ }^{54,55}$ In addition, we demonstrated frequent epigenetic silencing of CST6 in non-small cell lung cancer. $^{56}$ Although overall levels of endogenous cysteine protease inhibitor activity is decreased in gliomas and correlates with increasing tumor grade, ${ }^{57}$ the only other specific cystatin reportedly downregulated in primary brain tumors is cystatin $\mathrm{C}$. The mechanism behind the reduced expression of cystatin $\mathrm{C}$ in gliomas, however, has not been characterized. ${ }^{58}$

Numerous studies have demonstrated correlations between glioma grade, increased invasive properties in vitro, and upregulation of cathepsins $\mathrm{B}, \mathrm{D}$, and $\mathrm{L},{ }^{18,27-31}$ all of which are potential targets of cystatin E/M inhibition. Tumor cells at the invading edge of gliomas and infiltrating tumor cells express high levels of cathepsins, particularly cathepsin $\mathrm{B}^{26,59}$ Cathepsin B is particularly relevant because it is believed to be a central orchestrator of extracellular proteolytic activity. Once converted into its active form by uPA, tPA, or other cathepsins, cathepsin B not only possesses its own proteolytic activity against the ECM, but also activates the cascade to 

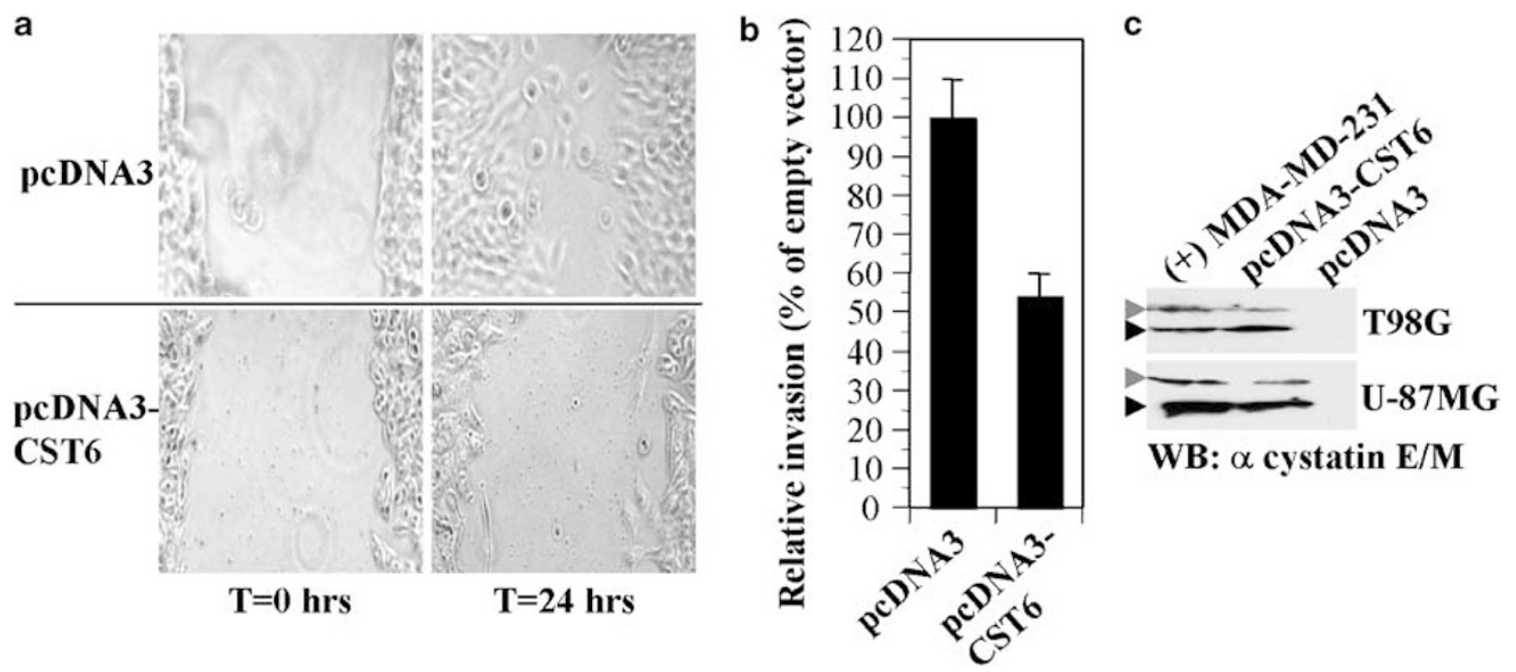

Figure 7 Ectopic expression of cystatin E/M suppresses glioma cell motility and invasion. (a) Scratch wound assay. T98G cells were transfected with empty vector (pcDNA3) or cystatin E/M expression vector (pCDNA3-CST6) and allowed to reach $\sim 90 \%$ confluence over $72 \mathrm{~h}$. The monolayer was then wounded with a plastic pipette tip, washed, and photographed over a period of $24 \mathrm{~h}$. U-87MG cells were not examined because they do not form a tightly packed monolayer. (b) Cell invasion assay. U-87MG cells were transfected with empty vector or cystatin E/M expression vector. After $24 \mathrm{~h}$, cells were replated into the Cultrex cell invasion assay kit (Trevigen), allowed to grow for an additional $24 \mathrm{~h}$ then cell invasion was measured and set relative to empty vector transfected cells. Similar results were obtained with T98G cells (data not shown). (c) Western blot demonstrating ectopic expression of cystatin E/M in T98G and U-87MG cells. The breast cancer cell line MDA-MB-231 served as a positive control for cystatin E/M expression. Upper and lower bands (gray and black arrowheads) correspond to the glycosylated and non-glycosylated forms of cystatin E/M, respectively.

convert plasminogen to plasmin. Plasmin has broad specificity including the ability to activate many MMPs such as MMP-2 and MMP-9, which in turn are capable of extensive degradation of collagen and other basal lamina proteins. Glioblastoma cell migration and matrigel invasion in vitro was substantially blocked by a synthetic cathepsin B inhibitor or RNAi-mediated knockdown of cathepsin B. ${ }^{28,60}$ Cathepsin $\mathrm{B}$ mRNA and protein levels directly correlated with evidence of clinical invasion assessed by magnetic resonance imaging. ${ }^{61}$ Consistent with its role as a cathepsin inhibitor, we observed that ectopic expression of CST6 resulted in both decreased motility and invasion of glioma cells in vitro suggesting that a combination of both cathepsin B upregulation and CST6 downregulation may contribute to glioma invasiveness. Therapies targeting both components may be particularly effective at reducing mortality.

We also showed for the first time that although normal neural stem cells express CST6, a glioma TIC did not. Multipotent progenitors with properties resembling cultured NSC have been described in vivo in the mammalian brain, predominantly in the subventricular zone beneath the lateral wall of the lateral ventricles and also in the subgranular zone in the dentate gyrus of the hippocampus. These cells are capable of differentiating into all cell types of the brain: neurons, astrocytes, and oligodendrocytes, and also functionally integrate into existing neuronal pathways. ${ }^{47}$ Interestingly in the rat, CST6 levels increased significantly upon induction of differentiation of an immortalized hippocampal cell line. ${ }^{32}$ Consistent with this, we detected a very marked increase in CST6 expression upon differentiation of NSC. It will be of interest to analyze the role of cystatin E/M in regulating NSC differentiation as well as the motility of these cells in vitro and in vivo. Also of interest was our finding that CST6 is epigenetically silenced in a glioma TIC. An exciting emerging area of cancer research posits that the bulk of the cells within a tumor have limited proliferative capacity and represent the aberrantly differentiated progeny of a cancer cell with stem cell like properties that has the capacity for unlimited self renewal. ${ }^{47}$ Intracranial injection of only a small number of TIC into immunocompromised mice results in robust tumor growth that phenocopies the original tumor, including, in the context of glioma, their highly infiltrative nature. ${ }^{37}$ These tumor stem cells, or tumor initiating cells, share many phenotypic properties with normal cultured neural stem cells, but an increasing number of differences are also being noted, including epigenetic differences. For example, it was recently reported that differentiation of some TIC in response to bone morphogenetic protein (BMP), unlike normal NSC, was impaired owing to DNA hypermethylation-mediated silencing of the BMP receptor $1 \mathrm{~B} .^{62}$ We have identified, to our knowledge, the second such aberrant differentiation-specific event in TIC, that CST6 induction upon TIC differentiation is blocked by promoter hypermethylation. TIC also appear more resistant to DNA-damaging chemotherapeutic agents and radiation. ${ }^{63}$ It will be of significant interest to determine the expression patterns of the cathepsins targeted by cystatin E/M in TIC as well as their degree of motility in vitro and in vivo. The 
observation that tumors reconstituted from TIC are highly infiltrative, coupled with our results that CST6 is silenced in this cell type, suggests that this event may contribute to the ability of TIC and/or their differentiated progeny to migrate and invade normal brain tissue. Additional studies of the protease/protease inhibitor balance in TIC warrants further study.

We also report here the first example of CST6 epigenetic silencing in pediatric brain tumors. Similarities and differences in the etiological, genetic, and epigenetic origins of pediatric and adult brain tumors have been suggested, but much remains unknown in this regard. ${ }^{64}$ Pediatric brain tumors tend to be of lower grade and have a better prognosis; however, they can also be as aggressive and invasive as adult primary brain tumors. Pilocytic astrocytoma is a slow growing grade I astrocytic tumor, which generally is non-invasive. Patients with this diagnosis may go many years without surgical intervention. Medulloblastomas, in contrast, are highly proliferative tumors, but in many cases do not invade. ${ }^{49}$ We observed that CST6 was downregulated in both of these pediatric tumor types (this paper and data not shown) although this appeared to be more a result of aberrant histone modifications than DNA hypermethylation in the case of pilocytic astrocytomas. That cystatin E/M expression is reduced in tumors showing little or no invasion supports the hypothesis from Keppler's group, in the context of breast cancer, that cystatin $\mathrm{E} / \mathrm{M}$ exerts a negative effect on tumor growth. Consistent with this notion, a microarray study comparing expression profiles of cystatin E/Mexpressing and non-expressing cells revealed that cystatin E/M directly or indirectly modulates gene expression. ${ }^{65}$ Further support for a growth regulatory role of cystatin E/M comes from the study of an oral cancer cell line, MDA-686Ln, which expresses cystatin E/M. In this study, siRNA knockdown of CST6 resulted in not only increased invasion and cathepsin activity, but also significantly enhanced cell proliferation. ${ }^{66}$ Our previous studies also suggested that ectopic expression of cystatin E/M suppressed the growth of glioma and NSCLC lines in colony-formation assays. ${ }^{10,56}$ Interestingly, a glycosylated form of cystatin $\mathrm{C}$ was shown to act as an autocrine/ paracrine-like factor for the growth of neural stem cells in culture. Cystatin $\mathrm{C}$ in the media was required for the mitogenic activity of FGF-2 on neural stem cells, supporting the notion that cystatin $\mathrm{E} / \mathrm{M}$ may have a role in cell growth independent of its protease inhibitor function. ${ }^{67}$ Growth inhibition by cystatin E/M may be owing to the ability of extracellular proteases, like the cathepsins and matrix metalloproteinases, to liberate bioactive fragments and growth factors (eg, TGF- $\beta$ ) and alter ECM architecture, both of which may modulate the growth and migratory behavior of cells. ${ }^{68}$ Inhibition of such protease activities by cystatin $\mathrm{E} / \mathrm{M}$ would therefore negatively regulate cell growth. Studies of alternative functions of cystatin $\mathrm{E} / \mathrm{M}$ in regulating cell growth and whether this effect is mediated through protease inhibition will be the subject of future studies.

\section{ACKNOWLEDGEMENTS}

This work was supported by NIH Grants R01CA114229 (KDR) and R01CA102289 (KDB). We thank Marda Jorgenson of the Histology Resource Center at the McKnight Brain Institute for providing technical assistance with the immunohistochemistry and immunofluorescence analyses, $\mathrm{Dr}$ David Brick of the National Neural Stem Cell Resource for culturing human neural stem cells, and the Florida Center for Brain Tumor Research for providing tissue samples.

1. Li E. Chromatin modification and epigenetic reprogramming in mammalian development. Nature Rev Genet 2002;3:662-673.

2. Baylin SB, Esteller M, Rountree MR, et al. Aberrant patterns of DNA methylation, chromatin formation and gene expression in cancer. Hum Mol Genet 2001;10:687-692.

3. Chen RZ, Pettersson U, Beard C, et al. DNA hypomethylation leads to elevated mutation rates. Nature 1998;395:89-93.

4. Eden A, Gaudet F, Waghmare A, et al. Chromosomal instability and tumors promoted by DNA hypomethylation. Science 2003;300:455.

5. Jones PA, Baylin SB. The fundamental role of epigenetic events in cancer. Nature Rev Genet 2002;3:415-428.

6. Costello JF, Fruhwald MC, Smiraglia DJ, et al. Aberrant CpG-island methylation has a non-random and tumor-type-specific patterns. Nature Genet 2000;25:132-138.

7. Bachman KE, Herman JG, Corn PG, et al. Methylation-associated silencing of the tissue inhibitor of metalloproteinase-3 gene suggests a suppressor role in kidney, brain, and other human cancers. Cancer Res 1999;59:798-802.

8. Sato N, Maehara N, Su SG, et al. Effects of 5-aza-2'-deoxycytidine on matrix metalloproteinase expression and pancreatic cancer cell invasiveness. J Natl Cancer Inst 2003;95:327-330.

9. Akiyama Y, Maesawa C, Ogasawara S, et al. Cell-type specific repression of the maspin gene is disrupted frequently by demethylation at the promoter region in gastric intestinal metaplasia and cancer cells. Am J Clin Pathol 2003;163:1911-1919.

10. Kim T-Y, Zhong S, Fields CR, et al. Epigenomic profiling reveals novel and frequent targets of aberrant DNA methylation-mediated silencing in malignant glioma. Cancer Res 2006;66:7490-7501.

11. Foltz G, Ryu G-Y, Yoon J-G, et al. Genome-wide analysis of epigenetic silencing identifies $B E X 1$ and $B E X 2$ as candidate tumor suppressor genes in malignant glioma. Cancer Res 2006;66:6665-6674.

12. Coopman PJ, Mueller SC. The syk tyrosine kinase: a new negative regulator in tumor growth and progression. Canc Lett 2006;241:159-173.

13. Ordway JM, Bedell JA, Citek RW, et al. Comprehensive DNA methylation profiling in a human cancer genome identifies novel epigenetic targets. Carcinogenesis 2006;27:2409-2423.

14. Gore SD, Baylin S, Sugar E, et al. Combined DNA methyltransferase and histone deacetylase inhibition in the treatment of myeloid neoplasms. Cancer Res 2006;66:6361-6369.

15. Laird PW. The power and the promise of DNA methylation markers. Nature Rev Canc 2003;3:253-266.

16. Mischel PS, Cloughesy TF, Nelson SF. DNA-microarray analysis of brain cancer: molecular classification for therapy. Nat Rev Neurosci 2004;5:782-792.

17. Ohgaki $H$, Kleihues P. Epidemiology and etiology of gliomas. Acta Neuropathol 2005;109:93-108.

18. Bellail AC, Hunter SB, Brat DJ, et al. Microregional extracellular matrix heterogeneity in brain modulates glioma cell invasion. Int J Biochem Cell Biol 2004;36:1046-1069.

19. Louis DN, Ohgaki H, Wiestler OD, Cavenee WK. WHO Classification of Tumors of the Central Nervous System. International Agency for Research on Cancer, 4th edn. IARC Press: Lyon, 2007.

20. Maher EA, Funari FB, Bachoo RM, et al. Malignant glioma: genetics and biology of a grave matter. Genes Dev 2001;15:1311-1333.

21. Baldwin RT, Preston-Martin S. Epidemiology of brain tumors in childhood-a review. Toxicol Appl Pharmacol 2004;199:118-131.

22. Pietsch T, Taylor MD, Rutka JT. Molecular pathogenesis of childhood brain tumors. J Neurooncol 2004;70:203-215.

23. Alonso ME, Bello MJ, Gonzalez-Gomez P, et al. Aberrant promoter methylation of multiple genes in oligodendrogliomas and ependymomas. Cancer Genet Cytogenet 2003;144:134-142. 
24. Gonzalez-Gomez P, Bello MJ, Lomas J, et al. Epigenetic changes in pilocytic astrocytomas and medulloblastomas. Int J Mol Med 2003;11:655-660.

25. Rao JS. Molecular mechanisms of glioma invasiveness: the role of proteases. Nature Rev Canc 2003;3:489-501.

26. Levicar N, Strijnik T, Kos J, et al. Lysosomal enzymes, cathepsins in brain tumour invasion. J Neurooncol 2002;58:21-32.

27. Mohanam S, Jasti SL, Kondraganti SR, et al. Down-regulation of cathepsin B expression impairs the invasive and tumorigenic potential of human glioblastoma cells. Oncogene 2001;20:3665-3673.

28. Yanamandra N, Gumidyala KV, Waldron KG, et al. Blockade of cathepsin B expression in human glioblastoma cells is associated with suppression of angiogenesis. Oncogene 2004;23:2224-2230.

29. Sivaparvathi M, Sawaya R, Wang SW, et al. Overexpression and localization of cathepsin B during the progression of human gliomas. Clin Exp Metastasis 1995;13:49-56.

30. Sivaparvathi M, Sawaya R, Chintala SK, et al. Expression of cathepsin D during the progression of human gliomas. Neurosci Lett 1996;208:171-174.

31. Abrahamson M, Alvarez-Fernandez M, Nathanson C-M. Cystatins. Biochem Soc Symp 2003;70:179-199.

32. Hong J, Yoshida K, Rosner MR. Characterization of a cysteine proteinase inhibitor induced during neuronal cell differentiation. J Neurochem 2002;81:922-934.

33. Ni J, Abrahamson $M$, Zhang $M$, et al. Cystatin $E$ is a novel human cysteine proteinase inhibitor with structural resemblance to family 2 cystatins. J Biol Chem 1997;272:10853-10858.

34. Shridhar R, Zhang J, Song J, et al. Cystatin M suppresses the malignant phenotype of human MDA-MD-435S cells. Oncogene 2004;23:22062215.

35. Zhang J, Shridhar R, Dai Q, et al. Cystatin M: a novel candidate tumor suppressor gene for breast cancer. Cancer Res 2004;64:6957-6964.

36. Schwartz PH, Bryant PJ, Fuja TJ, et al. Isolation and characterization of neural progenitor cells from post-mortem human cortex. J Neurosci Res 2003;74:838-851.

37. Lee J, Kotliarova $S$, Kotliarov $Y$, et al. Tumor stem cells derived from glioblastomas cultured in bFGF and EGF more closely mirror the phenotype and genotype of primary tumors than do serum-cultured cell lines. Cancer Cell 2006;9:391-403.

38. Ramachandran C, Khatib Z, Escalon E, et al. Molecular studies in pediatric medulloblastomas. Brain Tumor Pathol 2002;19:15-22.

39. Kononen J, Bubendorf L, Kallioniemi A, et al. Tissue microarrays for high-throughput molecular profiling of tumor specimens. Nature Med 1998:4:844-847.

40. Ai L, Kim W-J, Kim T-Y, et al. Epigenetic silencing of the tumor suppressor cystatin $\mathrm{M}$ occurs during breast cancer progression. Cancer Res 2006;66:7899-7909.

41. Widera D, Grimm W-D, Moebius JM, et al. Highly efficient neuronal differentiation of human somatic stem cells, isolated by minimally invasive periodontal surgery. Stem Cells Dev 2007;16:447-460.

42. Keppler D. Towards novel anti-cancer strategies based on cystatin function. Canc Lett 2006;235:159-176.

43. Frommer M, McDonald LE, Millar DS, et al. A genomic sequencing protocol that yields a positive display of 5-methylcytosine residues in individual DNA strands. Proc Natl Acad Sci USA 1992;89: 1827-1831.

44. Wolswijk G, Noble M. Identification of an adult-specific glial progenitor cell. Development 1989;105:387-400.

45. Herman JG, Graff JR, Myohanen S, et al. Methylation-specific PCR: a novel assay for methylation status of CpG islands. Proc Natl Acad Sci USA 1996;93:9821-9826.

46. Tost J, Gut IG. DNA methylation analysis by pyrosequencing. Nat Protoc 2007;2:2265-2275.

47. Sutter R, Yadirgi G, Marino S. Neural stem cells, tumour stem cells, and brain tumours: Dangerous relationships? Biochim Biophys Acta 2007;1776:125-137.
48. Li A, Walling J, Kotliarov Y, et al. Genomic changes and gene expression profiles reveal that established glioma lines are poorly representative of primary human gliomas. Mol Canc Res 2008;6:21-30.

49. Ullrich NJ, Pomeroy SL. Pediatric brain tumors. Neurol Clin 2003;21:897-913.

50. Cameron EE, Bachman KE, Myohanen S, et al. Synergy of demethylation and histone deacetylase inhibition in the re-expression of genes silenced in cancer. Nature Genet 1999;21:103-107.

51. Cheng $T$, Hitomi $K$, van Vlijmen-Willems IM, et al. Cystatin $M / E$ is a high affinity inhibitor of cathepsin $V$ and cathepsin $L$ by a reactive site that is distinct from the legumain-binding site. A novel clue for the role of cystatin M/E in epidermal cornification. J Biol Chem 2006;281: 15893-15899.

52. Goulet B, Baruch A, Moon NS, et al. A cathepsin L isoform that is devoid of a signal peptide localizes to the nucleus in $\mathrm{S}$ phase and processes the CDP/Cux transcription factor. Mol Cell 2004;14:207-219.

53. Hook VY. Unique neuronal functions of cathepsin $L$ and $B$ in secretory vesicles: biosynthesis of peptides in neurotransmission and neurodegenerative disease. Biol Chem 2006;384:1429-1439.

54. Rivenbark AG, Jones WD, Coleman WB. DNA methylation-dependent silencing of CST6 in human breast cancer cell lines. Lab Invest 2006;86:1233-1242.

55. Schagdarsurengin U, Pfeifer GP, Dammann R. Frequent epigenetic inactivation of cystatin $\mathrm{M}$ in breast carcinoma. Oncogene 2007;26:3089-3094.

56. Zhong S, Fields CR, Su N, et al. Pharmacologic inhibition of epigenetic modifications, coupled with gene expression profiling, reveals novel targets of aberrant DNA methylation and histone deacetylation in lung cancer. Oncogene 2007;26:2621-2634.

57. Sivaparvathi M, Mc Cutcheon I, Sawaya R, et al. Expression of cysteine protease inhibitors in human gliomas and meningiomas. Clin Exp Metastasis 1996;14:344-350.

58. Konduri SD, Yanamandra N, Siddique K, et al. Modulation of cystatin C expression impairs the invasive and tumorigenic potential of human glioblastoma cells. Oncogene 2002;21:8705-8712.

59. Mikkelsen T, Yan PS, Ho KL, et al. Immunolocalization of cathepsin B in human glioma: implications for tumor invasion and angiogenesis. J Neurosurg 1995;83:285-290.

60. Lakka SS, Gondi CS, Yanamandra N, et al. Inhibition of cathepsin B and MMP-9 gene expression in glioblastoma cell line via RNA interference reduces tumor cell invasion, tumor growth and angiogenesis. Oncogene 2004;23:4681-4689.

61. Rempel SA, Rosenblum ML, Mikkelsen $\mathrm{T}$, et al. Cathepsin B expression and localization in glioma progression and invasion. Cancer Res 1994;54:6027-6031.

62. Lee J, Son MJ, Woolard K, et al. Epigenetic-mediated dysfunction of the bone morphogenetic protein pathway inhibits differentiation of glioblastoma-initiating cells. Cancer Cell 2008;13:69-80.

63. Bao $\mathrm{S}, \mathrm{Wu} \mathrm{Q}, \mathrm{Mc}$ Lendon RE, et al. Glioma stem cells promote radioresistance by preferential activation of the DNA damage response. Nature 2006;444:756-760.

64. Kline NE, Sevier N. Solid tumors in children. J Pediatr Nurs 2003;18: 96-102.

65. Song J, Jie C, Polk P, et al. The candidate tumor suppressor CST6 alters the gene expression profile of human breast carcinoma cells: Downregulation of the potent mitogenic, motogenic, and angiogenic factor autotaxin. Biochem Biophys Res Commun 2006;340:175-182.

66. Vigneswaran $\mathrm{N}, \mathrm{Wu} \mathrm{J}$, Nagaraj $\mathrm{N}$, et al. Silencing of cystatin $\mathrm{M}$ in metastatic oral cancer line MDA-686Ln by siRNA increases cysteine proteinases and legumain activities, cell proliferation and in vitro invasion. Life Sciences 2006;78:898-907.

67. Taupin P, Ray J, Fischer WH, et al. FGF-2-responsive neural stem cell proliferation requires $\mathrm{CCg}$, a novel autocrine/paracrine cofactor. Neuron 2000;28:385-397.

68. Mott JD, Werb Z. Regulation of matrix biology by matrix metalloproteinases. Curr Opin Cell Biol 2004;16:558-564. 